\title{
Why are Fertility Rates and Female Employment Ratios Positively Correlated across O.E.C.D. Countries? ${ }^{\dagger}$
}

\author{
José María Da Rocha \\ RGEA-Universidade de Vigo \\ Luisa Fuster \\ University of Toronto \\ Universitat Pompeu Fabra
}

May 2005

\begin{abstract}
We develop a quantitative theory of fertility and labor market participation decisions in order to investigate the role of labor market frictions in generating the observed positive association between fertility and employment among O.E.C.D. countries. We find that unemployment induces females to postpone and space births which, in turn, reduces the total fertility rate. Moreover, differences in female labor outcomes across the U.S. and Spain can account for the low fertility rate in Spain relative to the U.S.. We also find that labor market frictions (low probability of finding a job) can generate a positive association between female employment ratios and fertility rates across economies.
\end{abstract}

$\dagger$ We are grateful to Andrés Erosa for many comments and suggestions. We also thank the comments of Pedro Mira, Diego Restuccia, José-Víctor Ríos-Rull, and three anonymous referees. We thank Miana Plesca for invaluable research assistance. We acknowledge the financial support of the BBVA foundation and the Ministerio de Ciencia y Tecnología through grants SEJ2004-03149 (L. Fuster) and SEC2002-4318-C02-01 (J. M. Da Rocha). 


\section{Introduction}

The goal of this paper is to explore the role of labor market frictions in generating recent observations of the total fertility rate and the female employment ratio (employment to population ratio) in O.E.C.D. countries. We introduce unemployment and the timing of births into an otherwise standard fertility-decision model and show that these features can go a long way in accounting for the positive association between the female employment ratio and the total fertility rate in O.E.C.D. countries during the period 1985-1996 (see Figure 1). The standard theory of labor market and fertility decisions, based on the seminal work of Mincer (1962) and Becker (1965), explains the secular trends of fertility rates and female participation rates in developed countries and abstracts from labor market frictions. According to this theory, the secular increase in female earning power raises the opportunity cost of the time allocated to child bearing which, in turn, induces females to participate in the labor market and to have less children. As a result, the theory implies a negative association between female participation and fertility rates.

\section{[Insert Figure 1]}

Our paper is motivated by some observations suggesting that unemployment can play a role in understanding the positive association between fertility rate and female employment ratio. For instance, in Sweden the fertility rate decreased significantly during the 90's when female and male employment fell (see Figures 7 and 9 in Section 4). In East Germany fertility rates collapsed at the same time that unemployment rose during the transition to democracy (Kreyenfeld, 2000). More generally, Ahn and Mira (2002) find that in most O.E.C.D. countries the fertility rate shows a negative response to unemployment along the business cycle (i.e., fertility is procyclical). In their empirical analysis using O.E.C.D. data, Ahn and Mira (2002) find that the cross-country correlation between female participation rates and fertility rates became of positive sign by the late 80's. They point out that the reverse of the sign of the cross-country correlation between participation and fertility rates 


\begin{tabular}{||l|rr||}
\hline \hline & Fertility & Unemployment \\
\hline U.S. & 2.02 & $4.5 \%$ \\
Sweden & 1.74 & $5.9 \%$ \\
Italy & 1.17 & $12.6 \%$ \\
Spain & 1.18 & $27.5 \%$ \\
\hline \hline
\end{tabular}

\section{Table 1: Fertility and Female Unemployment Rates in 1995}

occurred simultaneously with the emergence of high unemployment rates. Indeed, Spain and

Italy, which have exhibited the highest unemployment rates among O.E.C.D. countries, have also the lowest fertility rates as Table 1 shows (O.E.C.D. 1999).

We build a quantitative life cycle model of fertility and labor market decisions and show that labor market frictions can imply a positive correlation between fertility rates and employment ratios across economies. Following Ljungqvist and Sargent (1998), we assume that individuals search for a job and accumulate human capital on the job. We also assume that workers lose jobs with an exogenous probability and that human capital depreciates during job interruptions. We then extend the framework in Ljungqvist and Sargent (1998) in that individuals have a finite lifetime and do make fertility decisions. Moreover, in our model economy, females decide how to split their time between market activities (working and searching) and non-market activities (raising children and enjoying leisure).

We calibrate the steady state of our model to match some stylized facts of the U.S. economy. We then conduct some experiments to quantitatively evaluate the role of labor market frictions in accounting for cross-country and time series data on fertility rates. In one experiment, we recalibrate our benchmark economy so that it is consistent with the female participation and unemployment rates in Spain in 1995. Our goal is to evaluate how fertility decisions respond to changes in the labor market outcomes of females. We find that the fertility rate drops from 2.0 in our benchmark economy to 1.13 which is quite close to the actual fertility rate in Spain in 1995. We also find that births are postponed relative to the benchmark economy, which is consistent with the differential timing of births 
observed between the U.S. and Spain in 1995 (see Figure 4 in Section 4). In our economy, labor market frictions (low probability of finding a job) induce females to postpone births for two reasons. First, because children are intensive in mothers' time, females are likely to interrupt their career after giving birth to smooth consumption of leisure. A decrease in the job-finding rate increases the length of a career interruption and, thus, its cost in terms of forgone wages and human capital accumulation. By spacing births, females can avoid a costly career interruption. Second, as children are costly in terms of goods and as income is relatively low when females are young, they may postpone births in order to smooth the consumption of goods. The importance of these two effects increases with the incidence of unemployment among young females.

In a second experiment, we generate data for ten economies whose unemployment and participation rates are between the U.S. and Spanish levels in 1995. As a result, the unemployment and fertility rates of the model economies are in the range of values found in O.E.C.D. countries in 1995. We find that fertility and employment are positively associated across economies with different probabilities of finding a job. Our theory thus suggests that labor market frictions play an important role in understanding the positive association between fertility rates and employment ratios across O.E.C.D countries. Our findings also suggest that the correlation between employment ratios and fertility rates across countries may reverse its sign if the probability of finding a job increases.

In another experiment, we generate time-series data of total fertility rates and employment ratios of an economy that is affected by a transient unemployment shock. In the spirit of Ljungqvist and Sargent (1998), we assume that an unexpected shock that lasts one period increases job separation and partially destroys skills. Consistent with time-series observations for Sweden during the 90's, we find that the total fertility rate and the employment ratio jointly decrease.

Recent empirical research on O.E.C.D. countries lends support to the view that labor market institutions have a significant impact on fertility behavior. Del Boca (1999) estimates 
a reduced-form model of participation and fertility probabilities using Italian data. She finds that the availability of child care and part-time work increases both the probability of having a child and working. Adserà (2001) estimates a reduced-form model of fertility and age-specific birth rates using a panel of 23 O.E.C.D. countries covering 35 years. She finds a negative correlation between unemployment and fertility, which is especially strong since the 80's. Ahn and Mira (2001) estimate the impact of male unemployment on the hazard of marriage and births in Spain. They find that spells of non-employment have a strong negative effect on the hazard of marriage. Since in Spain most births occur within marriage, their findings suggest a negative impact of male unemployment on fertility. A contribution of our paper is to provide a quantitative framework of labor market and fertility decisions in which to study the impact of labor market frictions on fertility rates.

Our paper is related to quantitative studies on economics of the family. Most of these papers model marriage decisions and ignore the labor participation decision of women (see, for instance, Aiyagari, Greenwood and Guner (2000), Chade and Ventura (2002), Fernández and Rogerson (2001), and Regalia and Ríos-Rull (2001)). Similarly to us, Conesa (1999) and Caucutt, Guner and Knowles (2002) model the timing of births but they abstract from labor market decisions. Differently from this literature, our paper and that of Erosa, Fuster, and Restuccia (2002) model the interaction between labor market and fertility decisions. In particular, Erosa, Fuster, and Restuccia (2002) focus on the effect of fertility decisions on female labor-market turnover and the determination of the gender wage gap in the U.S.

The paper is organized as follows: The next section presents the model economy. Section 3 describes the calibration of our benchmark economy. Section 4 reports the results of the numerical experiments and Section 5 concludes the paper. 


\section{A Model of Fertility and Labor Participation Deci- sions}

We develop a model of female labor participation and fertility decisions that builds upon Ljungqvist and Sargent (1998). Following Ljungqvist and Sargent (1998), we assume that individuals search for a job and accumulate human capital on the job. We also assume that workers lose jobs with an exogenous probability and that human capital depreciates during job interruptions. We then extend the framework in Ljungqvist and Sargent (1998) in that individuals have finite lifetimes and make fertility decisions. Moreover, in our model economy, females decide how to split their time between market activities (working and searching) and non-market activities (raising children and enjoying leisure).

\subsection{The Economy}

\section{Demographics}

The economy is populated by overlapping generations of females that live $T$ periods as adults. Adult individuals make fertility and labor market decisions (while children do not make decisions). We assume that females receive opportunities to have children stochastically and that the probability of receiving a fertility opportunity decreases with age. This assumption is not only consistent with biological restrictions on female fertility but will also allow us to model the timing at which women give birth along their lifetime. As we shall see, labor market conditions will have consequences for the timing of births, which, in turn, will affect the total fertility rate.

\section{Preferences}

In our model, females derive utility from consumption, leisure, and the number of children they have. They maximize the expected present value of the per-period utility

$$
E\left\{\sum_{i=1}^{T} \beta^{i-1} u\left(c_{i}, l_{i}, N_{i}\right)\right\}
$$


where $\beta$ is the intertemporal discount factor, $i$ denotes an individual's age, and expectations are formed regarding the uncertainty about fertility opportunities and labor market shocks. We shall assume that the utility function is concave so that individuals have a desire to smooth consumption over time.

\section{Endowments}

For simplicity, we do not model labor decisions of husbands. Instead, we assume that

females are endowed with an age-profile of consumption goods $\omega \equiv\left(\omega_{1}, \omega_{2}, \ldots \omega_{T}\right)$ that we calibrate using data on husbands' earnings. In this way, we can study how females' decisions depend on the earnings of their husbands without adding too much complexity to the model. Females are born with an initial amount of human capital $h_{1}$ and an endowment of goods $\omega$, which are (jointly) drawn from a probability distribution $\Psi$. The distribution $\Psi$ will be calibrated to match the correlation of husbands' and wives' earnings in the data. Females are also endowed with one unit of time in each period of their lives which can be allocated to market and non-market activities. Market activities consist of working and searching for a job. Non-market activities consist of enjoying leisure and raising children.

\section{Market activities: Working and Searching}

One of the goals of our paper is to quantify the impact of labor market frictions on fertility and labor supply decisions of females. Following Ljungqvist and Sargent (1998), we introduce labor market frictions by assuming that individuals search for jobs. Searching is costly since it requires an exogenous fraction of time $z$. When females search, they obtain a job opportunity with probability $\pi$. A job is given by a linear production technology on the human capital of the worker. We assume that an exogenous fraction of production technologies (jobs) $\lambda$ are terminated each period. Females without a job choose whether they want to search in the labor market or not. We emphasize the importance of modeling female labor market participation. The data show that women participate less than men 
and that this is particularly true for women with children. Moreover, there are important cross-country differences in female employment and participation rates and we are interested in understanding how these differences affect birth rates across countries.

\section{Human capital accumulation}

We would like our quantitative theory to exhibit heterogeneity on wages across females because fertility decisions are affected by female earnings. At the same time, it is important that our model economy captures the cost that children impose on females' human capital accumulation. To this end, we assume that human capital is accumulated while a female is working and that it depreciates while she is not working. As a result, career interruptions associated with childbirth can be quite costly for mothers.

A female with human capital $h$ who works earns $w h \bar{l}$, where $w$ represents market luck and $\bar{l}$ the (fixed) amount of hours worked. Human capital varies across females because they are born with different amounts of initial human capital and because they have different labor market histories. In our framework, labor market experience affects labor productivity because human capital is accumulated on the job. We assume that human capital grows at a rate $\varepsilon_{i}$ when an age- $i$ female works. Moreover, consistently with the evidence reported by Mincer and Ofek (1982), we assume that human capital depreciates at a rate $\delta_{i}$ when an age $-i$ female does not work. We note that the rates at which human capital grows and depreciates depend on age for reproducing an empirically plausible age-wage profile. Because labor market experience and the initial amount of wage heterogeneity is not enough to account for the earnings inequality in the data, we introduce a stochastic component of labor productivity representing labor market luck. We assume that market luck is given by $w=e^{u_{t}}$, where $u_{t}$ follows a first-order Markov process $u_{t}=\rho u_{t-1}+\varepsilon_{u, t}, \varepsilon_{u, t} \backsim N\left(0, \sigma_{\varepsilon}^{2}\right)$.

\section{Costs of raising children}

We assume that children are costly in terms of mothers' time and goods. ${ }^{1}$ The time

\footnotetext{
${ }^{1}$ There is evidence that family status affects how women allocate their time between market and non-
} 
cost reduces mothers' consumption of leisure and may induce them not to participate in the labor market, which is consistent with the lower employment rates of mothers relative to non-mothers in the U.S. economy. We assume that 'young' children are more time costly than 'old' children. We introduce this assumption in a computational simple way by modeling two types of children: time-intensive (young) and non-time intensive (old) children. All children are born as time-intensive and become non-time intensive with a fixed probability. Non-time intensive children remain so until the end of their childhood. The expected length of the time-intensive period is calibrated to last 6 years. ${ }^{2}$ For notational convenience, we will refer to time-intensive children as "children younger than 6 ".

In our model, children are also costly in terms of goods. We assume a child-care cost that is incurred while mothers spend time on market activities (working and searching). In particular, time-intensive children require one unit of child-care services for every hour that their mothers allocate to market activities. As a result, mothers have less incentives to work than non mothers. In addition, each child requires $\varkappa$ units of consumption goods per period. The fixed cost $\varkappa$ imposes a limit on the number of children in families with a low income (households where both the husband's and wife's income are low).

\subsection{The Decision Problem of Females}

It is convenient to assume that females make labor market and fertility decisions at different stages. In a first stage, females decide whether or not to participate in labor market activities: Females with job offers decide whether or not to accept one while females without job offers decide whether or not to search for one. In a second stage, in each possible employment state (employed, searching or not searching), females make a fertility decision. Once the fertility

market activities. In fact, according to Hill (1981) women spend $25 \%$ of their time working at home when they work full time in the market, while men spend only $12 \%$ of their time working at home. The difference between male and female time allocated in home production is higher if women work part time. In this case, they spend $34 \%$ of their time working at home.

${ }^{2}$ The stochastic duration of the time-intensive stage is convenient for computational reasons. Under this specification, the age distribution of children is not a state variable in the decision problem of females. We only need to know the number of children in the time-intensive stage and the total number of children. 
decision is made, both the level of consumption and the level of leisure are known. Notice that non-fertile females only decide whether or not to participate in market activities similar to individuals in Ljungqvist and Sargent's (1998) framework. At the end of the period, individuals face labor market and fertility shocks.

\section{The first stage: Choosing whether to participate or not in market activities}

At the beginning of a period, females decide whether or not to participate in labor market activities: working and searching for a job. Females without a job offer decide to search if the utility of searching $\left(V_{S}\right)$ is higher than the utility associated with not searching $\left(V_{N S}\right)$. The indirect utility associated with not having a job-offer, $W_{n o}$, is thus given by

$$
W_{n o}(s) \equiv \max \left\{V_{S}(s), V_{N S}(s)\right\},
$$

where $s=\left(f, N, N_{6}, h, \omega, i, u\right)$ summarizes the state of an individual at the first stage regarding fertility status ( $f=1$ means having a fertility opportunity), number of children $N$, number of children younger than $6 N_{6}$, human capital $h$, endowment of goods $\omega$, age $i$, and labor market luck $u$.

Females with a job offer decide to work if the indirect utility associated with working $\left(V_{e}\right)$ is larger than the indirect utility associated with not having a job-offer $W_{n o}$. Thus, the indirect utility associated with having a job offer is

$$
W_{o}(s) \equiv \max \left\{V_{e}(s), W_{n o}(s)\right\} \text {. }
$$

The following diagram describes the decision problem of females depending on whether or not they have a job offer at the beginning of the period: 


\section{$V_{e}$ Utility if she accepts}

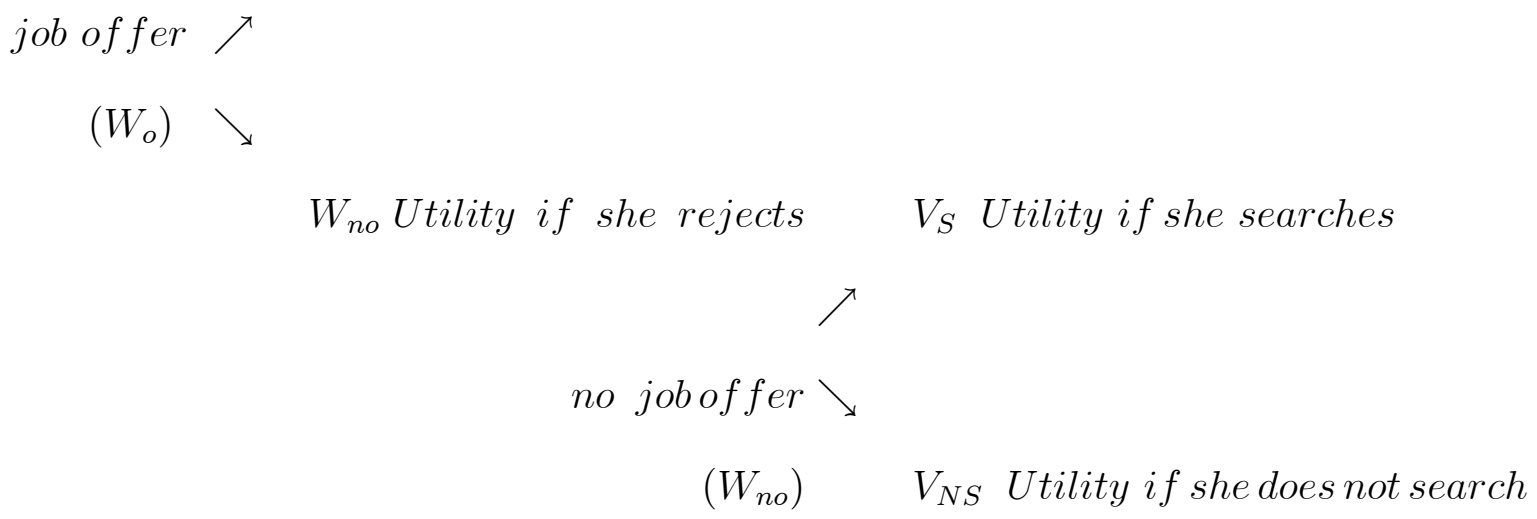

\section{Second stage: Fertility decision}

The decision to give birth depends, among other things, on the labor market status of females (working, searching, or not participating) since this status affects the cost of having children. When females work, they allocate a fixed amount of time $\bar{l}$ to work (obtaining earnings $w h \bar{l}$ ) and must buy one unit of child care services per hour worked and per child younger than age 6 . When females search, they allocate a fixed amount of time $z$ to search and must also buy one unit of child-care services per hour of market activity and per each 
child younger than 6 . The decision problem of a working female is given by

$$
\begin{aligned}
V_{e}\left(f, N_{6}, N, h, \omega, i, u\right)= & \underset{\{c, l, n\}}{\operatorname{Max}}\left\{u(c, l, N+n)+\beta E_{f^{\prime} \phi u^{\prime} / u}\left[\lambda W_{n o}\left(f^{\prime}, N_{6}^{\prime}, N^{\prime}, h^{\prime}, \omega, i+1, u^{\prime}\right)\right.\right. \\
& \left.\left.+(1-\lambda) W_{o}\left(f^{\prime}, N_{6}^{\prime}, N^{\prime}, h^{\prime}, \omega, i+1, u^{\prime}\right)\right]\right\}
\end{aligned}
$$

subject to :

$$
\begin{aligned}
& n \in\{0,1\} \text { if } f=1 ; \text { otherwise } n=0 \\
& N^{\prime}=N+n ; N_{6}^{\prime}=N_{6}+n-\phi \\
& h^{\prime}=h\left(1+\varepsilon_{i}\right) \\
& c+\varkappa(N+n)+p_{c h} \bar{l}\left(N_{6}+n\right)=\omega_{i}+e^{u} h \bar{l} \\
& l+\tau_{1}\left(N_{6}+n\right)+\tau_{2}\left(N-N_{6}\right)=1-\bar{l},
\end{aligned}
$$

where there are expectations of next-period indirect utility over the distributions of fertility opportunities, $f$, number of children that become older than $6, \phi$, and the productivity shock, $u^{\prime}$. The first of the constraints implies that females can choose whether or not to have an additional child when they have a fertility opportunity. The next two equations are the law of motion of the total number of children $N$ and the number of children younger than $6, N_{6}$. The number of children younger than 6 increases with the newborn $n$, and decreases with the number of children who become old, $\phi$. The third equation is the law of motion of the female's human capital which indicates that human capital grows at a rate $\varepsilon_{i}$ when an age- $i$ female works. The last two equations are the budget constraint and the time constraint. The budget constraint restricts the sum of consumption, expenditure on raising children, and child-care services to be lower than the sum of goods endowment and earnings, where we assume that the cost of a unit of child-care services is equal to $p_{c h}$ units of consumption goods. The time constraint restricts the sum of leisure, and the time allocated to child bearing to be equal to the endowment of time minus the time allocated to working. Notice that $\tau_{1}$ is the time cost for a time-intensive child and $\tau_{2}$ is the time cost for the other children. 
Also, notice that if the female works and the job is not exogenously destroyed (an event that occurs with probability $\lambda$ ) the female will start the next period with a job.

The decision problem of a female who searches for a job is given by

$$
\begin{aligned}
V_{S}\left(f, N_{6}, N, h, \omega, i, u\right)= & \operatorname{Max}_{\{c, l, n\}}\left\{u(c, l, N+n)+\beta E_{f^{\prime} \phi u^{\prime} / u}\left[\pi W_{o}\left(f^{\prime}, N_{6}^{\prime}, N^{\prime}, h^{\prime}, \omega, i+1, u^{\prime}\right)\right.\right. \\
& \left.\left.+(1-\pi) W_{n o}\left(f^{\prime}, N_{6}^{\prime}, N^{\prime}, h^{\prime}, \omega, i+1, u^{\prime}\right)\right]\right\}
\end{aligned}
$$

subject to :(3), (4) and

$$
\begin{aligned}
& h^{\prime}=h\left(1-\delta_{i}\right) \\
& c+\varkappa(N+n)+p_{c h} z\left(N_{6}+n\right)=\omega_{i} \\
& l+\tau_{1}\left(N_{6}+n\right)+\tau_{2}\left(N-N_{6}\right)=1-z .
\end{aligned}
$$

where the expectation of next-period indirect utility is taken over the distributions of fertility opportunities, $f$, number of children that become older than $6, \phi$, the productivity shock, $u^{\prime}$, and the distribution of offers, $\pi$. The law of motion of human capital (8) indicates that skills depreciate at a rate $\delta_{i}$ when an age $-i$ female does not work. The budget constraint (9) and the time restriction (10) determine the consumption of goods and leisure. Notice that when individuals search they spend $z$ units of time on market activities.

We assume that females who do not participate in labor market activities (work or search), start the next period without a job. The decision problem of a female who does not participate in labor market activities is given by

$$
\begin{aligned}
V_{N S}\left(f, N_{6}, N, h, \omega, i, u\right)= & \underset{\{c, l, n\}}{\operatorname{Max}}\left\{u(c, l, N+n)+\beta E_{f^{\prime} \phi u^{\prime} / u} W_{n o}\left(f^{\prime}, N_{6}^{\prime}, N^{\prime}, h^{\prime}, \omega, i+1, u^{\prime}\right)\right\} \\
\text { subject to }:(3),(4),(8) \text { and } & \\
& c+\varkappa(N+n)=\omega_{i} \\
& l+\tau_{1}\left(N_{6}+n\right)+\tau_{2}\left(N-N_{6}\right)=1 .
\end{aligned}
$$


When a female does not work, her human capital depreciates at the rate $\delta_{i}$. Because she does not participate in market activities, she enjoys more leisure, and she does not need to buy child-care services. Notice that the female draws a realization of the productivity shock $u^{\prime}$ which affects the wage that she will obtain in the future if she decides to work ${ }^{3}$

The Bellman equations for non-fertile females are a particular case of the ones above (where $n$ is exogenously set to 0 ). Non-fertile females do not take any decision in the second stage and their labor market status determines their consumption and leisure.

\section{Discussion.}

It is worth discussing the key factors affecting fertility decisions in our model economy. The benefit of having a child is the increase of present and future utility since children are a durable consumption good. In terms of the costs of children, they involve goods and leisure costs in the present as well as in the future. Because the cost of children depends on the labor status of the mother, fertility and labor supply decisions are not independent of each other in our framework. The leisure cost is relatively less important if the female does not participate because, in this way, she enjoys the highest possible leisure (relative to working or searching). The goods costs are given by a fixed cost and a child-care cost. The fixed cost is most costly, in terms of utility, if the female searches than if she does not because in that case her consumption is the lowest (and the marginal utility of consumption the highest relative to the case of working or not participating). The child care cost is paid only if she participates in the labor market, either working or searching. The fact that participating in the labor market implies a child care cost may discourage mothers to return to the labor market. Mothers may decide to stay out of the labor force until their children become older than 6 when both the marginal utility of leisure and the child care cost decrease. The cost of child care relative to consumption is higher if the mother searches than if she works because consumption is lower when the mother searches. In summary, the present costs of giving

\footnotetext{
${ }^{3}$ This assumption generates heterogeneity among non-participating females of similar observable characteristics. Heterogeneity is important in our model because participation decisions are discrete.
} 
birth are lower if the female either works or does not participate in the market than if she decides to search.

The labor and fertility decisions also depend on the future costs implied by children. The future costs are the forgone wages and the loss of human capital experienced by females who interrupt their career to have a child. Human capital is lost because skills accumulate on the job and depreciate while not working. The future cost induces females to keep their job after giving birth, and its importance depends on the female characteristics. There are several female characteristics that favor a career interruption due to fertility. First, since the time cost is higher when children are younger than 6, females with young children may prefer not to participate in the labor market in order to smooth consumption of leisure. Second, a female with a high-income husband is more likely to quit the job because her marginal utility of consumption is low. Third, a female with high human capital faces a high opportunity cost of quitting a job and is less likely to interrupt her career after giving birth. To summarize, females with richer husbands, lower human capital or/and several young children are more likely to interrupt their career after giving birth than otherwise.

The probability for a female of finding a job affects the cost of interrupting a career after she gives birth. The cost of interrupting a career is higher the longer it takes to come back to the labor market (more skills are lost). As a consequence, the longer the duration of unemployment, the more costly it is to interrupt a career. When the probability of finding a job is low (the unemployment rate is high), working females may want to avoid a career interruption because of fertility. To this end, they would space their births which reduces the number of time-intensive children and, thus, the time cost of children.

For non-fertile females, labor supply decisions are simpler. Our model implies that they are less willing to participate in the labor market as they age. In this way, they smooth consumption given that their endowment profile is increasing with age. Moreover, other things being equal, high human capital females are more willing to participate than low human capital females. In our model, females with the same age and endowment can differ 
in their level of human capital because of different labor-market histories and initial human capital. Females also may differ with respect to the realization of the wage shock. If the realization of the wage shock is good, they are more willing to work than otherwise.

\subsection{Stationary Population Growth}

In this economy, the rate of growth of the female population is endogenously determined by the fertility decisions of females. Since one of the targets of our calibration is a constant population growth rate, it is convenient to define stationary population growth in our model. When population growth is stationary, the relative sizes of cohorts are constant over time. We define the relative size of age- $i$-cohort as the ratio of its size to the size of the age$\left(t_{1}+1\right)$-cohort (adult of age 1 ), where $t_{1}$ is the age at which children become adults. When population grows at a constant rate $\eta$, the relative size of age- $i$-cohort is constant and equal to $(1+\eta)^{t_{1}+1-i}$ for all $i=\left\{1,2, \ldots, t_{1}+T\right\}$.

The relative size of the new-born generation is given by the sum of children born from fertile cohorts $\left(t_{1}+1\right.$ to $\left.t_{1}+t_{2}\right)$. Since the relative size of the new-born generation is equal to $(1+\eta)^{t_{1}}$, the stationary population growth rate must satisfy the following equation

$$
\begin{aligned}
(1+\eta)^{t_{1}}= & 0.5 *\left(\sum_{s} n(s, 1) \digamma_{1}(s)+(1+\eta)^{-1} \sum_{s} n(s, 2) \digamma_{2}(s)+\ldots\right. \\
& \left.+(1+\eta)^{1-t_{2}} \sum_{s} n\left(s, t_{2}\right) \digamma_{t_{2}}(s)\right)
\end{aligned}
$$

where $n(s, i)$ is the optimal policy of fertility, where $s$ denotes the state of an age $i$ household, $s=\left(f, N, N_{6}, h, \omega, u\right)$, and where $\digamma_{i}$ denotes the distribution of states $s$ across households of age $i$. In other words, the right-hand side of the above equation is the weighted sum of births across fertile households with different states. This sum is multiplied by 0.5 because we assume that half of the births are female newborns. The weights used in the sum are the relative sizes of generations times the measure of individuals of a given age $i$ with state $s .{ }^{4}$

\footnotetext{
${ }^{4}$ Given the initial distribution $\digamma_{1}(s)$ of states across households of age 1 , the measures $\digamma_{i}(s)$, for $i=$
} 


\section{The Benchmark Economy}

In this section we choose functional forms and parameter values such that the steady state of this economy is consistent with some selected observations of the U.S. economy in 1995. In calibrating the model economy, the value of some parameters can be chosen with no need to solve the model. The value of these parameters are shown in Table 2 . The calibration of the other parameters involves solving the model economy and their values are shown in Table 3. Although the mapping between parameters and allocations in our model is non-trivial, some parameters have a first-order impact on some of the targeted statistics. Below, we describe how we use U.S. statistics to pin down the value of parameters in our economy (but it should be understood that our calibration procedure solves for all the parameters in Table 3 simultaneously).

\section{Time and demographic parameters}

We choose the model period to be one year. A shorter model period will significantly increase the computational cost of solving our model. We assume that females become adults at age 20, receive fertility opportunities during the first 20 years of adulthood, and die when they are 80 years old. Fertility opportunities decrease with age, reflecting a biological restriction. ${ }^{5}$ In particular, we assume that the probability of being fertile is equal to 1 from ages 20 to 30 , decreases at a constant rate from 1 to $p_{1}$ for ages 30 to 35 and from $p_{1}$ to $p_{2}$ for ages 35 to $40 .{ }^{6}$ We choose values for $p_{1}$ and $p_{2}$ in order to match the 1995 U.S. average birth rates of women in the age groups 30-34 and 35-40.

\section{Utility}

$2, \ldots T$, are endogenously determined by individuals' decisions and the demographic and labor market shocks.

${ }^{5}$ Fertility studies show that the fertility clock starts ticking at the mid 30's. At this age, the monthly chance of pregnancy drops from 25-30 percent to 10-15 percent. At age 40 this chance is less than 5 percent with a 40 percent chance of miscarriage.

${ }^{6}$ For any age $i \in[30,35]$, we set the fertility opportunity to be $\left[1-\left(\frac{1-p_{1}}{5}\right)(i-30)\right]$, where $p_{1}<1$. For any age $i \in[35,40]$, we set the fertility opportunity to be $\left[p_{1}-\left(\frac{p_{1}-p_{2}}{5}\right)(i-35)\right]$, where $p_{2}<p_{1}$. 
We assume the per-period utility function to be $u(c, l, N)=\alpha_{1} \log c+\log l+\alpha_{2} \log (\bar{N}+N)$. The parameters $\alpha_{1}, \alpha_{2}$ and $\bar{N}$ are chosen to match the participation rate of females, total fertility rate, and the birth rate of the age group 20-30. The calibration of the utility parameter $\bar{N}$ plays an important role in determining the timing of births in our benchmark economy. This observation can be understood by considering the case of $\bar{N}=0$. In this case, the increase in utility due to the first child is plus infinity so that all females will choose to have the first child immediately. An increase in the parameter $\bar{N}$, while keeping constant the cost of children, decreases the utility value of having the first child so that some young females may decide to postpone the first birth. The parameters $\left(\alpha_{1}, \alpha_{2}, \bar{N}\right)$ are calibrated by solving the model as it is explained below. The discount factor of utility $\beta$ is set to 0.96 (which implies an annual discount rate of 4 percent).

\section{Convexification of the Fertility Decision}

To facilitate our calibration we convexify the fertility decision in order to ensure that fertility decisions in our model economy respond smoothly to changes in the parameters values. Following Regalia and Ríos-Rull (2001), we assume that individuals spend effort in achieving their desired fertility outcome (either having a child or not). The level of effort that individuals choose $(s)$ determines the probability of having a child $\frac{\kappa e^{-s}}{e^{s}+\kappa e^{-s}}$. Spending an amount of effort $s$ involves a disutility cost of $c s^{2}{ }^{7}$

The convexification of the fertility decision introduces two new parameters to the model $(\kappa$ and $c$ ). We choose the value of the parameter $\kappa$ so that the probability of having a child (given by the optimal effort) is equal to 0.5 when the individual is indifferent between having an additional child or not. The cost parameter $c$ determines the fraction of individuals that have an undesired outcome. In principle, we would like to set this fraction as small as possible so that our approximation to a model with a discrete fertility choice is more accurate. In the benchmark economy, the fraction of individuals that have an undesired outcome regarding their fertility choice is 0.25 percent.

\footnotetext{
${ }^{7}$ Notice that the probability of having a child is decreasing with effort and that it tends to 0 when effort tends to $\infty$ while it tends to 1 when effort tends to $-\infty$.
} 


\section{Stochastic process of productivity}

We estimate the stochastic process of labor productivity using data on female earnings from the Panel Study on Income Dynamics (PSID). Using the surveys of 1972 to 1993, we construct a panel of observations from households where both the head and spouse are between 25 to 64 years old and work at least 775 hours per year. ${ }^{8}$ We estimate the following equation in our panel:

$$
\log w_{i t}=\varrho X_{i t}+\nu_{i}+u_{i t}
$$

where $w_{i t}$ are real annual earnings of female $i$ at time $t, \nu_{i} \backsim N\left(0, \sigma_{\nu}^{2}\right)$ represents a time invariant unobserved individual heterogeneity, and $u_{i t}=\rho u_{i t-1}+\varepsilon$ where $\varepsilon \sim N\left(0, \sigma_{\varepsilon}^{2}\right)$. The variables considered in $X_{i t}$ are education, race, work experience (full time and part time), experience squared, hours worked, age, age squared, marital status, number of children, dummy for the presence of children younger than 6 years old, and annual dummy variables. The estimated parameters of the $\operatorname{AR}(1)$ process for $u$ are $\widehat{\rho}=0.58$ and $\widehat{\sigma}_{\varepsilon}=0.29$ the estimates of the other coefficients are shown in the Appendix. In the benchmark calibration we approximate the $\operatorname{AR}(1)$ process for $u$ by a five-state Markov chain following Tauchen (1986). The grid for $u$ and the transition probability matrix are

$$
u=\left[\begin{array}{r}
-1.08 \\
-0.54 \\
0 . \\
0.54 \\
1.08
\end{array}\right] ; P=\left[\begin{array}{ccccc}
0.2623 & 0.6226 & 0.1139 & 0.0012 & 0.0 \\
0.045 & 0.511 & 0.4199 & 0.0239 & 0.0002 \\
0.003 & 0.1763 & 0.6414 & 0.1763 & 0.003 \\
0.0001 & 0.0239 & 0.4199 & 0.511 & 0.0451 \\
0.0 & 0.0012 & 0.1139 & 0.6226 & 0.2623
\end{array}\right] .
$$

\section{Endowments of goods and initial human capital}

We assume a lognormal distribution of the initial human capital with mean 0 and standard

\footnotetext{
${ }^{8}$ Males are on average 2 years older than females.
} 
deviation $\sigma_{h_{1}} \cdot{ }^{9}$ To make our model computationally tractable, we discretize the support of the distribution of initial human capital to 4 values. For each initial level of human capital we need to assign a distribution of endowment of goods (representing husbands' earnings). We assume that the log of female human capital and husband earnings are related as follows

$$
\log \left(\omega_{1}^{i j}\right)=c_{0} \log \left(h_{1}^{i}\right)+c_{1}+c_{2}(j-1)
$$

where $c_{0}, c_{1}, c_{2}$ are parameters,$i \in\{1,2,3,4\}$ is the index of females' initial human capital and $j \in\{1,2,3,4\}$. We assume each value of $j$ has probability $1 / 4$ so that females with human capital $h_{i}$ face a uniform probability distribution over 4 possible values of the endowment of goods. It should be intuitive that the parameter $c_{0}$ directly affects the correlation of a female's human capital with her endowment of goods. The parameter $c_{1}$ can be pinned down using data on gender earning gaps (the larger $c_{1}$, the larger is the endowment relative to females' human capital). The parameter $c_{2}$ has consequences for the variance of the initial endowment. Given the initial endowment of goods, a constant growth rate determines the endowment at subsequent ages. The growth rate of the endowment is calibrated to be consistent with the lifetime growth of the average husband's earnings of our PSID sample. ${ }^{10}$ To summarize, we need to pin down the parameters $\left(\sigma_{h_{1}}, c_{0}, c_{1}, c_{2}\right)$ in order to determine the joint distribution of initial human capital and endowment of goods. These parameters are calibrated by solving the model, as we explain later.

\section{Human capital accumulation}

We assume that, for simplicity, human capital remains constant after age 45 and that for younger individuals human capital grows and depreciates at a constant rate (depending on labor market status). We then have two parameters to calibrate $(\varepsilon, \delta)$. These parameters

\footnotetext{
${ }^{9}$ The mean of the distribution of the log of initial human capital is set to zero as a normalization.

${ }^{10}$ We assume that the endowment grows at an annual rate of 3 percent from ages 20 to age 48 and it decreases at a constant rate of 3 percent from age 48 to age 60. We use cross-section data for the year 1993 (the last year or our sample) to compute the age-profile of the average earnings of husbands. Since we find that husbands' earnings peak when their wives are, on average, 48 years old we assume that the endowment grows up to age 48 and it decreases since then.
} 
will have a first-order impact on the mean wage growth for females ages 20 to 45 and on the inequality of wages for females at age 45. These parameters will be obtained by solving the model.

\section{Cost of children}

Hofferth and Wissoker (1991) report a child-to-staff ratio in child-care services of $6.67 .^{11}$ Assuming that workers in the child-care service have the average initial human capital level $(h=1)$ and an average market luck $(u=0)$, the cost of one unit of child-care services can be approximated by $1 / 6.67$. The time that mothers spend raising children is chosen to match the impact of children in hours worked by women reported in McGrattan and Rogerson (1998). We obtain an average time spent with a child younger than 6 years old of $\tau_{1}=0.072$, and an average time spent with a child older than 6 years of $\tau_{2}=0.034 .^{12}$

\section{Shocks}

We assume that workers searching for jobs find a job with probability one. This rate seems reasonable because the average unemployment duration in the U.S. economy is lower than one year. Because our model period is one year, a separation from a job implies a one-year unemployment spell. We then assume a conservative job separation rate of $5 \% .{ }^{13}$ The parameter representing the search cost, $z$, is chosen to match the unemployment rate

\footnotetext{
${ }^{11}$ These authors examine data from the National Longitudinal Survey of Youth (NLSY) on child care arrangements in 1985. An important advantage of the NLSY data on child care is that it provides a nationally representative sample of the 1979 population in the U.S. economy. Our choice for the child-staff ratio is also consistent with the estimates reported by Blau (1999).

${ }^{12}$ We obtain values of these parameters using data on hours worked by women in 1990, as reported by McGrattan and Rogerson (1998). Using these data, we find that mothers of children older than 6 work 5.725 more hours per week than mothers with children younger than 6 . We use this number as an estimate of how the time cost of children decreases with the age of the child. In particular, we assume that $n\left(\tau_{1}-\tau_{2}\right)=0.05725$ where $n$ denotes the average number of children of mothers of ages 25-44 years old (which is about 1.5). Since married women have on average one more child than single women, and since married women work 5.31 less hours per week than single women we set the average time cost per child to be .0531 , that is, $\frac{\tau_{1}+\tau_{2}}{2}=0.0531$. Solving these two equations in two unknowns we obtain that $\tau_{1}=0.072$ and $\tau_{2}=0.034$.

${ }^{13}$ For instance, Clark (1990) reports a $15 \%$ transition rate from employment to non employment in the U.S. economy in 1974.
} 


\section{Table 2: Parameters Calibrated without Solving the Model}

\begin{tabular}{||l|l||}
\hline \hline Parameter value & Parameter meaning \\
\hline Demographics & Years duration of adulthood. \\
\hline$T=60$ & Years duration of childhood. \\
$t_{1}=20$ & Fertile years. \\
$t_{2}=20$ & Age-growth rate of husband's earnings \\
\hline Endowments & from age 20 to age 48 \\
\hline$\left(\omega_{i} / \omega_{i-1}-1\right)$ & from age 49 to age 60 \\
$3 \%$ & Full-time working time. \\
$-3 \%$ & Probability of a job offer. \\
\hline Market activities & Probability being laid-off. \\
$\bar{l}=0.40$ & AR(1) process of the shock on wages \\
$\pi=1.00$ & Time raising children younger 6. \\
$\lambda=0.05$ & Time raising children older than 6. \\
$u$ & Price of child care \\
\hline Non market activities \\
\hline$\tau_{1}=0.072$ & \multicolumn{2}{||}{} \\
$\tau_{2}=0.034$ & Discount factor \\
$p_{\text {ch }}=1 / 6.67$ & Utility
\end{tabular}

of women in the U.S. in 1995.

We assume that the probability that a young child becomes 6 years old is 0.83 , which implies that, on average, it takes 6 years for a child to become a 6 -year old. The number of children that become older than $6(\phi)$ follows a binomial distribution.

\section{Parameters calibrated by solving the model}

Summarizing our previous discussion, there are thirteen parameters that are jointly calibrated by solving the model: the preference parameters for consumption $\alpha_{1}$ and number of children $\left(\alpha_{2}, \bar{N}\right)$, the parameters that give the fertility opportunities $\left(p_{1}, p_{2}\right)$, the parameters describing the joint distribution of initial human capital and endowment of skills $\left(\sigma_{h_{1}}, c_{0}, c_{1}\right.$, $\left.c_{2}\right)$, the parameters describing depreciation and growth rates of human capital $(\delta, \varepsilon)$, the cost of searching $z$, and the expenditure per child $\varkappa$. These parameters are pinned down so that 


\section{Table 3: Parameters Calibrated by Solving the Model}

\begin{tabular}{||ll|r||}
\hline \hline Parameters & & Calibration Targets \\
\hline$\alpha_{1}=2.47$ & Utility of consumption & Activity rate of women ages 20-54 \\
$\alpha_{2}=0.97$ & Utility of children & Total fertility rate \\
$\bar{N}=1.71$ & Utility of children & Births at ages 20-24/Total births. \\
$p_{1}=0.46$ & Fertility opportunity Age 30. & Births at ages 30-34/Total births. \\
$p_{2}=0.25$ & Fertility opportunity Age 35. & Births at ages 35-40/Total births. \\
$\sigma_{h_{1}}=.43$ & Variance initial human capital & Gini earnings of wives \\
$c_{0}=0.5$ & Initial endowment & Correlation husbands \& wives log earnings \\
$c_{1}=-0.44$ & Initial endowment & Gender earnings ratio at age 20 \\
$c_{2}=0.35$ & Initial endowment & Gini of earnings of husbands \\
$\delta=0.049$ & Depreciation rate younger than 45 & Wives' mean wage age 45 /age 21 \\
$\varepsilon=0.046$ & Growth rate of skills younger than 45 & Gini earnings of age 45 wives \\
$z=0.34$ & Searching cost. & Unemployment rate of women ages 20-54. \\
$\varkappa=0.24$ & Child's consumption. & Expenditure on children/GDP \\
\hline \hline
\end{tabular}

the steady state of the model reproduces the following thirteen targets from the U.S. economy: The labor force participation rate of women between ages 20 and 54; the total fertility rate; the birth rates at ages 20-24, 30-34 and 35-40; the Gini coefficient of earnings of wives in the 1993 PSID sample; the Gini coefficient of earnings of husbands in the 1993 PSID sample; the correlation between wages of husbands and wives; the gender earnings ratio at age 20; the mean females' earnings at age 45, the Gini of earnings of wives at age 45 in the 1993 PSID sample, the unemployment rate and the expenditure on children to GDP ratio.

It is worth discussing some of our calibration targets. Since we want to study the impact of labor market decisions on the timing of births, we need our model to be consistent with realistic birth-age profiles. Our calibration targets the birth rates of women belonging to age groups 20-24, 25-29, 30-34 and 35-40 in 1995 which are obtained from the U.S. Bureau of Census (1997). According to O.E.C.D. data, in the U.S. economy in 1995, the participation rate of women between ages 20-54 was 76 percent, the unemployment rate of women between ages 20-54 was 4.5 percent, and the fertility rate was 2.02 (O.E.C.D. 1999). The target for the ratio of children's expenditures to GDP is 0.15 , which is the number reported by Haveman 
and Wolfe (1995) for the U.S. economy.

One of the targets in our calibration is the empirical correlation of husbands' and wives' log-earnings. We estimate this correlation with the following regression on our PSID panel of households

$$
\log w_{i t}^{H}=\gamma Z_{i t}+\xi_{i} ; \xi_{i} \backsim N\left(0, \sigma_{\xi}^{2}\right)
$$

where $w_{i t}^{H}$ are real annual earnings of the husband in household $i$ in period $t$, and the variables included in $Z_{i t}$ are the logarithm of earnings potential of wives and a year dummy. The earnings potential of wives is defined as the predicted earnings $\widehat{\varrho} X_{i t}$ by our estimated equation (13), assuming that (annual) hours worked are equal to two thousand (full-time workers). We obtain an estimate for the log earnings' correlation of husbands and wives of 0.55 .

We use our PSID sample (1993 cross-section) to obtain a value of .35 for the Gini coefficients of wives' earnings and a value of .33 for the Gini coefficient of husbands' earnings. The Gini coefficient of earnings of 45 years old wives is 0.33 in the 1993 PSID sample. The target for the gender earnings ratio at age 20 is set at $0.8 .{ }^{14}$ The mean wage of women age 45 relative to the female mean wage at age 20 is 2.2 in our PSID sample.

\subsection{Calibration Results}

In Table 4 we show that our benchmark economy matches our calibration targets well. In Figure 2, we plot the number of births by age groups relative to the total number of births for both the U.S. economy and our benchmark economy. The figure shows that the benchmark economy matches the timing of births well (with the caveat that the birth rate of the youngest group is slightly higher than in the data and that the birth rates of the groups 25-29 and

\footnotetext{
${ }^{14}$ The earnings gender ratio equals the product of the wage ratio times the ratio of hours worked by women to the hours worked by men. McGrattan and Rogerson (1998, Tables 8-9) report that the ratio of working hours of women to men was 0.89 for individuals of ages 15-24 in 1990. Moreover, Blau and Kahn (2000) report a gender wage ratio of 0.93 for individuals of ages 18-24 in the year 1998. Using these two observations, our estimate of the earnings ratio for individuals around 20 years old is $0.89 * 0.93=.82$, which give us a gender earnings gap of about $20 \%$.
} 
Table 4: Benchmark Economy: Calibration Results.

\begin{tabular}{||l|rr||}
\hline \hline & U.S. Data & Benchmark Economy \\
\hline Activity rate ages 20-54 & $76 \%$ & $77.06 \%$ \\
Total fertility rate & 2.02 & 2.0 \\
Births at ages 20-24/Total births & 0.30 & 0.326 \\
Births at ages 30-34/Total births & 0.29 & 0.285 \\
Births at ages 35-40/Total births & 0.12 & 0.116 \\
Gini earnings of wives & 0.35 & 0.347 \\
Correlation husbands \& wives log earnings & 0.54 & 0.55 \\
Gender earnings ratio at age 20 & 0.80 & 0.83 \\
Gini earnings of husbands & 0.33 & 0.30 \\
Wives' mean wage age 45 /age 21 & 2.2 & 2.48 \\
Gini earnings of age 45 wives & 0.33 & 0.35 \\
Unemployment rate of women ages 20-54 & $4.5 \%$ & $4.86 \%$ \\
Expenditure on children/GDP & $15 \%$ & $16 \%$ \\
\hline \hline
\end{tabular}

35-39 are slightly lower than in the data).

\section{[Insert Figure 2]}

Since the timing of births plays an important role in the numerical experiments that follow, it is worth discussing the key factors affecting the age-profile of births in our economy. Because children are a durable consumption good, females who give birth at an early age can obtain utility from children during more periods, a force that induces females to become mothers when young. However, females may prefer to postpone births because the costs of children may decrease with age. When females are young, they expect their consumption to grow over time (due to the growth of their wages and endowment of goods) so that their marginal utility of consumption is likely to decrease as they age. Because children are costly in terms of goods, the desire to smooth consumption may induce females to have their children later on. Similarly, because newborns are intensive in mothers' time, the desire to smooth consumption of leisure may induce females to space births. This effect is specially important among females who participate in the labor market: By spacing births, they can avoid a costly career interruption. Females who do not participate in the labor market may 


\section{Table 5: Birth Rates per 1000 Women by Labor Force Status}

\begin{tabular}{||l|r|r||}
\hline \hline & Benchmark & U.S. 1995 \\
\hline In the labor force & 65 & 47 \\
Not in the labor force & 79 & 98 \\
\hline \hline
\end{tabular}

find it optimal to have children early on when their wages are low (the opportunity cost of a career interruption is low). In the next section, we shall see that unemployment exacerbates some of the effects just described.

Cross-sectional implications. Our theory has implications on how birth rates and number of children vary across women by labor force status, age, and income levels. We can compare these implications to the U.S. data. Using C.P.S. data we document the following observations on the U.S. economy (see Table 5, Table 6, Table 7, and Table 8): ${ }^{15}$

1. Birth rates are higher among women who are out of the labor force than among women in the labor force.

2. The average number of children is higher among women who are out of the labor force than among women in the labor force.

3. When we divide the women in the U.S. economy into income groups, we find that the second observation holds for all income levels.

4. The birth rate decreases as family income increases.

While our benchmark economy was not calibrated to match the above observations, it is roughly consistent with them. In particular, our benchmark economy is consistent with the relationship between birth rates and labor force status and the relationship between number of children and labor force status observed in the U.S. economy. Birth rates are higher among

\footnotetext{
${ }^{15}$ The data source is the publication "Fertility of American Women: June 1995 (Update)" of the Census Bureau (see Bachu 1997) which reports data collected by the Current Population Survey (C.P.S.) in 1995.
} 
Table 6: Number of Children by Labor Force Status

\begin{tabular}{||c|c|c||}
\hline \hline & $\begin{array}{c}\text { Benchmark } \\
\text { (35 to 39 years old })\end{array}$ & $\begin{array}{c}\text { U.S.1995 } \\
\text { (35 to 44 years old })\end{array}$ \\
\hline In labor force & 1.78 & 1.96 \\
Not in labor force & 2.32 & 2.44 \\
\hline \hline
\end{tabular}

Table 7: Ratio of Number of Children: Women out of the Labor Force to Women in the Labor Force.

\begin{tabular}{||c|c|c||}
\hline \hline Family Income percentiles & $\begin{array}{c}\text { Benchmark } \\
(20 \text { to 39 years old })\end{array}$ & $\begin{array}{c}\text { U.S.1995 } \\
\text { (15 to 44 years old })\end{array}$ \\
\hline $0-29$ & 1.66 & 1.38 \\
$30-49$ & 1.64 & 1.24 \\
$50-69$ & 1.30 & 1.24 \\
$70-100$ & 1.23 & 1.20 \\
\hline \hline
\end{tabular}

females out of the labor force than among females in the labor force, both in our benchmark economy and in the data. In the benchmark economy, females out of the labor force give birth to 24 more children per thousand women than females in the labor force, but in the data the difference is 51 births per thousand women (see Table 5). The relationship between fertility and labor force status has long-lasting effects on the life cycle of women since, both in the benchmark economy and in the U.S. data, women out of the labor force have (on average) about 0.5 more children than women in the labor force (see Table 6 ). We also find that being out of the labor force is associated with a higher number of children for women in different income groups (see Table 7).

Our benchmark economy does not match well the association between birth rates and family income in the U.S. data (see Table 8). While birth rates decrease monotonically with income in the U.S. economy, the relationship between birth rates and family income is not monotonic in our benchmark economy. In particular, the birth rate among women in the bottom income group is very low relative to the data. In understanding this observation, the reader should bear in mind that our theory abstracts from welfare policies that may 


\section{Table 8: Birth Rates per 1000 Women and Family Income}

\begin{tabular}{||c|r|r||}
\hline \hline Family Income percentiles & Benchmark & U.S. 1995 \\
\hline $0-29$ & 17 & 81 \\
$30-49$ & 98 & 62 \\
$50-69$ & 71 & 58 \\
$70-100$ & 85 & 49 \\
\hline \hline
\end{tabular}

encourage women with low family income in the U.S. economy to stay out of the labor force. Moreover, we have not modeled single motherhood and education which are likely to be important in accounting for the low labor participation and the high fertility of women in the lowest income group in the U.S. economy. ${ }^{16}$

In our benchmark economy, the birth rate of women in the top income group is higher than the birth rate of women in the second highest income group. In our theory, women in the top group of family income are quite likely to be out of the labor force and to have many children because they have, on average, a high endowment.

\section{$4 \quad$ Numerical Experiments}

In this section we investigate the consistency of our model with the cross-country and time-series evidence on employment ratios and fertility rates. In a first experiment, we quantitatively evaluate the extent to which the high female unemployment and low femaleparticipation rates in Spain (relative to the U.S.) can explain the low fertility rate in this country (relative to the U.S.). We then perform several sensitivity analyses to gain insights on the interaction between fertility and labor market decisions across economies with different labor market frictions. In particular we focus on the role of labor market frictions

\footnotetext{
${ }^{16}$ To the extent that education is positively associated with female labor participation in the U.S. economy (after controlling for family income) and that our theory abstracts from education, it should not be surprising that low income females exhibit high participation in the labor market (and thus low fertility) in our benchmark economy relative to the data. The same reasoning implies that high income women exhibit too low labor participation (and high fertility) in our theory relative to the data.
} 
(probability of finding a job) to understand the positive correlation between female employment and fertility rates observed across O.E.C.D. economies (see Figure 1). In a second experiment, we quantify the effects of a temporary unemployment shock on fertility and participation rates. The goal of this experiment is to investigate if our theory can shed some light on recent time-series observations in Sweden regarding employment and fertility rates.

\subsection{The Spanish Experiment}

In this experiment, we compare both the fertility rate and the timing of births of two economies that differ in the labor participation and unemployment rates of females. This experiment is motivated by the large differences in the fertility rates between the U.S. and Spain (1.18 in Spain and 2.02 in the U.S. in 1995) and by the high female unemployment and the low female-participation rates of Spain relative to the U.S.. We recalibrate our benchmark economy in order to reproduce the unemployment and participation rates of females in Spain in 1995, and we let the fertility rate be determined endogenously by our quantitative theory. Notice that by matching both the unemployment and participation rates of females in Spain, we match the unemployment-to-population ratio (the incidence of female unemployment in the Spanish economy). To this end, we recalibrate the probability of finding a job, and we change the endowment of females by a constant proportion. Essentially, we reduce the probability of finding a job (relative to the benchmark economy), and we decrease the endowment of females to match our targets. Intuitively, a reduction in the probability of finding a job increases the unemployment rate and reduces the participation rate. In order to match the participation rate in Spain, we reduce the females' endowment by 30 percent (otherwise, the participation rate in our recalibrated model economy would be too low relative to the Spanish data).

Table 9 shows that we are able to match our targets well for the unemployment and 
Table 9: The Spanish Experiment: Calibration Results.

\begin{tabular}{||l|r|r||}
\hline \hline & \multicolumn{1}{|c||}{ Model } & \multicolumn{1}{c|}{ Data } \\
& "Spanish Case" & Spain 1995 \\
\hline Unemployment rate & $25.5 \%$ & $27.5 \%$ \\
Participation rate & $52.6 \%$ & $54 \%$ \\
\hline \hline
\end{tabular}

Table 10: The Spanish Experiment: Implications for Fertility.

\begin{tabular}{|c|c|c|}
\hline & $\begin{array}{c}\text { Model } \\
\text { "Spanish Case" }\end{array}$ & $\begin{array}{c}\text { Data } \\
\text { Spain } 1995\end{array}$ \\
\hline Fertility rate & 1.13 & 1.18 \\
\hline Percentage of births at ages: & & \\
\hline $20-24$ & 14.9 & 13 \\
\hline $25-29$ & 33.5 & 37 \\
\hline $30-34$ & 33.9 & 37 \\
\hline $35-40$ & 17.7 & 13 \\
\hline
\end{tabular}

participation rates. ${ }^{17}$ We can then ask how much the fertility rate changes relative to the benchmark economy and how this change compares with the difference between the fertility rates in the U.S. and Spain. We find that the fertility rate in the Spanish experiment is quite close to the fertility rate in Spain (see Table 10). ${ }^{18}$ When the unemployment and participation rates are recalibrated to the Spanish targets, the fertility rate drops from 2.02 in our benchmark economy to 1.13. Figure 3 shows that the reduction of the total fertility rate is associated with a postponement of births. In particular, the percentage of births that occur between ages 20-24 drops from 32 percent to less than 15 percent. Because females have a finite fertile lifetime, it should not be surprising that the total fertility rate decreases when births are postponed. The implication of our theory regarding the timing of births is also consistent with the Spanish data (see Table 10). In Spain, mothers give birth, on

\footnotetext{
${ }^{17}$ The data source is OECD (1999). The participation and unemployment rates correspond to women between 25-54 years old.

${ }^{18}$ The data sources are OECD (1999) for the total fertility rate and INE ("Instituto Nacional de Estadística") of Spain for the age-birth rates.
} 
average, at a later age than in the U.S. (see Figure 4).

\section{[Insert Figure 3]}

\section{[Insert Figure 4]}

There are two main reasons that explain the postponement of births in the Spanish experiment. First, in order to smooth the consumption of leisure, females are likely to interrupt their career after giving birth because children are intensive in mothers' time. A decrease in the job-finding rate increases the length of a career interruption and, thus, its cost in terms of forgone wages and human capital accumulation. By spacing births, females can avoid a (costly) career interruption. Second, because children are costly in terms of goods and because income is relatively low when females are young, females may postpone births in order to smooth the consumption of goods. The importance of the two effects increases with the incidence of unemployment among young females.

In order to gain some insights about how labor market decisions interact with fertility, we can compare the number of children among females with different labor market status (employed, unemployed, and out of the labor force). Relative to the benchmark economy, we find that in the "Spanish experiment" females have a lower number of children, regardless of their labor market status. When we consider females that are employed or out of the labor force, the average number of children is about $50 \%$ lower in the "Spanish experiment" than in the benchmark economy. When we consider unemployed females, we find that the average number of children is about $80 \%$ lower in the "Spanish experiment" than in the benchmark economy. These observations suggest that the low fertility rate in the "Spanish experiment" is mostly explained by young females searching for jobs.

It is interesting that the Spanish data seem to support the idea that labor market frictions affect the timing of births. In Spain, during the period 1976 to 1995, the fertility rate decreased and births were postponed (see Figure 4). During this period, female unemployment increased significantly, which suggests that labor market frictions affected the timing of births and fertility rates in Spain. Some authors point out that the demographic changes 
in Spain can be explained by the increase in the schooling attainment of women (see, for instance, Bover and Arellano (1994) and Conesa (1999)). However, this explanation cannot account for the differences in the timing of births between Spain and the U.S.. Indeed, women in Spain give birth, on average, at a later age than women in the U.S. while their education attainment is lower than the one of U.S. women. We conclude that the increase in education attainment cannot be the only reason why births have been postponed in Spain during the last 20 years. Our view is supported by a recent fertility survey conducted in Spain (INE 1999, "Encuesta de Fecundidad"). In this survey, 68 percent of the women interviewed responded that they have not completed their desired family size because of an economic restriction.

We would like to stress that in our framework labor market frictions (probability of finding a job less than 1), determine how employment and fertility are associated. To illustrate this idea, we fix exogenously the probability of finding a job to 1 and recalibrate our benchmark model economy to match the employment ratio in Spain (notice that we do not target the unemployment rate in Spain, differently from our Spanish experiment ). To this end, we change by a constant fraction the female's endowment of goods. We find that the fertility rate is now 3.17 and that females tend to have children early. In other words, a decrease in the female employment ratio is now associated with an increase in fertility. Labor market frictions thus affect the sign of the correlation between fertility and employment.

\section{The correlation between fertility rates and employment ratios across economies.}

To further illustrate how employment and fertility rates relate in our framework, we consider 10 economies that are convex combinations of the benchmark and Spanish experiment economies (recall that these two economies differ in the probability of finding a job and the female endowment of goods). In this way, we generate economies in which the unemployment and participation ratios are between the U.S. and Spanish levels. ${ }^{19}$ Figure 5 compares the unemployment and participation ratios generated by this experiment with the data from

\footnotetext{
${ }^{19} \mathrm{~A}$ table in the Appendix shows the parameter values used and the data generated in this experiment.
} 
O.E.C.D countries in 1995. We find that the data generated by this experiment reveals a positive association between employment ratio and fertility rate (see Figure 6). As the probability of finding a job decreases and the endowment decreases, the unemployment rate increases and the participation rate decreases generating the negative association displayed in Figure 5. Figure 6 shows that fertility and employment are positively associated across the model economies with low probability of finding a job.

\section{[Insert Figure 5] \\ [Insert Figure 6]}

We conclude that cross-country differences in female employment ratios can generate a positive correlation between fertility rates and employment ratios of females when the jobfinding rate is low. Our findings suggest that the sign of the correlation could reverse in the future as the job-finding rate of females increases. Indeed, recent O.E.C.D. data show that the cross-country correlation between employment ratio and fertility rate is significantly reduced (from 0.63 to 0.23 ) once countries with high unemployment rates (Italy, Spain and Greece) are eliminated from the sample (see Figure 6).

The next experiment investigates some time-series implications of our quantitative theory.

\subsection{The Swedish Experiment}

In this section we perform an experiment that is motivated by recent time-series observations from Sweden. In Sweden during the period 1990-1997, the fertility rate decreased by 28 percent while the female-employment ratio fell 18 percent and the unemployment rate experienced a 5-fold increase (see Figures 7 and 8). ${ }^{20}$ Moreover, between 1990 and 1993 male employment experienced a 14-percent decrease (see Figure 9). It is interesting that employment and fertility follow similar time trends in Sweden and in the U.S. up to 1990,

\footnotetext{
${ }^{20}$ The data source is the OECD Health and Labor Statistics (1999). The employment ratio is computed for females of age between 15-54 years old.
} 
but that after that period they follow different trends. While there was a sharp decrease in the fertility rate in Sweden, the fertility rate in the U.S. remained roughly constant (or, if anything, showed a slight increase). Suggestively, in Sweden the unemployment rate experienced a 5-fold increase while the U.S. employment ratio increased during the 90's. (see Figure 8).

We follow Ljungqvist and Sargent (1998) in considering an economy that experiences a one-time shock that induces a 10-fold increase of the lay-off rate and that reduces 50 percent of the skills of individuals upon a job separation. ${ }^{21}$ The lay-off rate and the depreciation rate of skills are set as in the benchmark economy in the period after the shock takes place. Notice that since we are modeling a one-time unexpected shock, the optimal decisions of individuals are the same as in the benchmark economy. The transient shock, however, does affect the distribution of states across individuals, the relative sizes of future cohorts, and all aggregate statistics in the model economy.

\section{[Insert Figure 7] \\ [Insert Figure 8] \\ [Insert Figure 9]}

We find that, as in Ljungqvist and Sargent (1998), the one time shock has persistent effects on employment and inequality (see Figures 10 and 11). The employment ratio decreases by 44 percent in one period and remains below its steady state value for a long time. The response of then fertility rate to the transient economic shock is shown in Figure 12. When the shock hits the economy, the total fertility rate decreases by 20 percent. The shock induces a decrease in birth rates for all age groups and a postponement of births. The timing effect is dramatic since the percentage of total births by young mothers (ages 20 to 30) decreases from 60 percent to only 20 percent. The total fertility rate increases the next period for two reasons. First, some females who postponed births decide to have children

\footnotetext{
${ }^{21}$ Hoem (1999) reports an increase in the proportion of low income females during the 90's in Sweden.
} 
one period after the shock occurs. Second, the new generation that enters the economy is not affected by the shock and has a high birth rate relative to the 20 -years-old born at the moment of the shock.

\section{[Insert Figure 10] \\ [Insert Figure 11] \\ [Insert Figure 12]}

\section{Conclusions}

This paper builds a quantitative theory of labor supply and fertility decisions in order to understand recent observations of fertility rates and employment ratios in O.E.C.D. countries. Our findings can be summarized as follows: First, we find that the low fertility rate in Spain relative to the U.S. is accounted for by the high-female unemployment and low female-participation rates in Spain relative to the U.S.. Our theory also implies that labor market frictions (probability of finding a job less than 1) induce a postponement in births, an implication consistent with the timing of births in Spain. Second, we find that labor market frictions determine how employment and fertility are associated across economies. In particular, fertility and employment are positively associated across economies with low employment ratios (low probability of finding a job). On the other hand, fertility and employment are negatively associated across economies with a high probability of finding a job. Our findings suggest that the sign of the correlation between employment ratios and fertility rates across countries could change as the job-finding rate of females increases. Third, motivated by some recent time-series observations in Sweden, we show that a transient job destruction shock in the economy leads to a transient reduction in fertility and a postponement of births. We conclude that labor market frictions are key for understanding the behavior of fertility rates in countries where women participate in the labor market.

We conjecture that the effect of an unemployment shock on fertility rates can be large in 
economies with parental leave policies of the type instituted in Sweden. In Sweden, parental leave benefits are proportional to mothers' wages. The proportionality of the benefits induces workers to postpone births until they reach the desired level of benefits. An increase in unemployment or a depreciation of skills increases the time necessary to reach such a level of benefits and, thus, enhances the incentive to postpone births. We plan to study these issues in future work.

\section{Appendix}

In this appendix, we present more detail about the results of the wage regressions mentioned in the Calibration section and the numerical experiment on the correlation between fertility rates and employment ratios across economies.

Using data from the Panel Study on Income Dynamics (PSID), the surveys of 1972 to 1993, we construct a panel of observations of households. We select households where both the head and spouse are between 25 to 64 years old and work at least 775 hours per year. We estimate the following equation in our panel:

$$
\log w_{i t}=\varrho X_{i t}+\nu_{i}+u_{i t}
$$

where $w_{i t}$ are real annual earnings of female $i$ at time $t, \nu_{i} \backsim N\left(0, \sigma_{\nu}^{2}\right)$ represents the time invariant unobserved individual heterogeneity, and $u_{i t}=\rho u_{i t-1}+\varepsilon$ where $\varepsilon \sim N\left(0, \sigma_{\varepsilon}^{2}\right)$. The variables considered in $X_{i t}$ are education, race, work experience (full time and part time), experience squared, hours worked, age, age squared, marital status, number of children, dummy for the presence of children younger than 6 years old, and annual dummy variables. Table 11 shows the estimated coefficients of the G.L.S. estimation for a random effects model. The estimated parameters of the AR(1) process for $u$ are $\widehat{\rho}=0.58$ and $\widehat{\sigma}_{\varepsilon}=0.29$. 


\section{Table 11: Results estimation of model for wives' log earnings}

\begin{tabular}{||lll||}
\hline \hline Variable & Estimate coef. & Std.Err. \\
\hline EDU & .078 & $2.3 \mathrm{E}-03$ \\
RACE1 & -.1126 & $1.4 \mathrm{E}-02$ \\
RACE2 & $-.0138^{*}$ & $2.1 \mathrm{E}-02$ \\
EXP & .0213 & $1.5 \mathrm{E}-03$ \\
EXPSQR & -.00028 & $3.9 \mathrm{E}-05$ \\
HOURS & .00037 & $4.2 \mathrm{E}-06$ \\
AGE & .027 & $3.2 \mathrm{E}-03$ \\
AGESQR & -.00039 & $3.9 \mathrm{E}-05$ \\
MARRIED & -.0328 & $7.9 \mathrm{E}-03$ \\
CHILD & -.04151 & $3.1 \mathrm{E}-03$ \\
CHILD6 & -.01321 & $6.1 \mathrm{E}-03$ \\
Constant & 9.90 & .071 \\
\hline R-sq & .7223 & \\
N. Obs. & 50340 & \\
$*$ Not signifficant. & \\
\hline \hline
\end{tabular}

List of variables: EDU: 5 education categories. RACE1: Dummy for black. RACE2: Dummy for non white and non black. EXP: Years of experience. EXPSQR: Experience squared. HOURS: Hours worked. AGE, AGESQR: Age and age squared. MARRIED: Dummy for married status. CHILD: Number of children. CHILD6: Number of children younger than 6 .

All coefficients are significant at $1 \%$ level but for CHILD6 which is significant at $5 \%$ level and RACE2 which is not significant at $10 \%$ level. Notice that children have a negative impact on women's earnings. 
Table 12: The Spanish Experiment: The correlation between fertility rates and employment ratios across economies

\begin{tabular}{||lllllll||}
\hline \hline Economies & $\boldsymbol{\pi}_{i} / \pi_{1}$ & $\boldsymbol{\omega}_{i} / \omega_{1}$ & Particip. & Unemp. & Emplo. & Fertility \\
\hline $\mathbf{1}$ (Benchmark) & 1 & 1 & 77 & 4.86 & 73.3 & 2.0 \\
$\mathbf{2}$ & .91 & .96 & 78 & 5.48 & 73.97 & 1.93 \\
$\mathbf{3}$ & .82 & .93 & 79 & 6.25 & 74.3 & 1.86 \\
$\mathbf{4}$ & .73 & .90 & 79.8 & 7.22 & 74 & 1.78 \\
$\mathbf{5}$ & .64 & .86 & 79.3 & 8.4 & 72.7 & 1.70 \\
$\mathbf{6}$ & .55 & .83 & 78.8 & 9.9 & 70.9 & 1.61 \\
$\mathbf{7}$ & .46 & .80 & 77.2 & 11.9 & 68.05 & 1.51 \\
$\mathbf{8}$ & .37 & .76 & 73.6 & 14.7 & 62.78 & 1.41 \\
$\mathbf{9}$ & .28 & .73 & 66.6 & 18.6 & 54.24 & 1.28 \\
$\mathbf{1 0}$ ("Spanish exp.") & .19 & .70 & 52.6 & 25.06 & 39.45 & 1.13 \\
\hline \hline
\end{tabular}

The Table 12 presents data on the correlation between fertility rates and employment ratios across model economies. These model economies are convex combinations of the Benchmark and the "Spanish experiment" economies. Table 12 also shows the parameter values used to construct these model economies. The second column shows the ratio of the probability of finding a job in economy $i$ to the probability of finding a job in the benchmark economy. The third column shows the ratio of the endowment in economy $i$ to the endowment in the benchmark economy. 


\section{References}

[1] Aiyagari, R., J. Greenwood, and N. Guner. (2000). "On the State of the Union". Journal of Political Economy, vol. 108, 213-44.

[2] Adserà, A. (2001). "Changing Fertility Rates in Developed Countries. The Impact of Labor Market Institutions." Mimeo. University of Illinois at Chicago.

[3] Ahn, N. and P. Mira, (2001). "Job Bust, Baby Bust?: Evidence from Spain." Journal of Population Economics, vol. 14, 505-521.

[4] Ahn, N. and P. Mira, (2002). "A Note on the Changing Relationship between Fertility and Female Employment in Developed Countries." Journal of Population Economics, vol. 15(4), 667-682.

[5] Bachu, A. (1997). "Fertility of American Women: June 1995 (Update)". Current Population Reports. Bureau of Census, U.S. Department of Commerce. Internet address: http://www.census.gov/prod/3/97pubs/p20-499.pdf.

[6] Becker, G. S. (1965). "A Theory of the Allocation of Time." Economic Journal, vol. 75, 493-517.

[7] Blau, D. M. (1999). "The Effect of Child Care Characteristics on Child Development". Journal of Human Resources 34 (4), pp. 786-818.

[8] Blau, D., and L. M. Kahn, (2000). "Gender Differences in Pay." Journal of Economic Perspectives, vol. 14 (4), 75-99.

[9] Bover, O. and M. Arellano (1994). "Female Labour Force Participation in the 1980s: The Case of Spain.” Working paper 9427. Banco de España.

[10] Bureau of Census (1997). Population statistics. Internet address: http://www.census.gov/population/socdemo/fertility/fert95/tabH1.txt. 
[11] Caucutt, E., N. Guner, and J. Knowles. (2002). "The Timing of Births: A Marriage Market Analysis." Review of Economic Dynamics , vol. 5(4), 815-855.

[12] Chade, H. and G. Ventura. (2002). "Taxes and Marriage: A Two-sided Search Analysis." International Economic Review, vol. 43, 955-86.

[13] Clark, K. B. (1990). "Unemployment insurance and labor market transitions." In L. Summers, eds., Understanding Unemployment, Cambridge, M.A. : MIT Press.

[14] Conesa, J.C. (1999). "Education Attainment and Timing of Fertility Decisions." Mimeo. University of Minnesota.

[15] Del Boca, D. (2002). "The Effect of Child Care and Part Time Opportunities on Participation and Fertility Decisions in Italy." Journal of Population Economics, vol. 15, 549-573.

[16] Erosa, A., L. Fuster, and D. Restuccia (2002). "Fertility Decisions and Gender Differences in Labor Turnover, Employment, and Wages." Review of Economic Dynamics, vol. 5(4), 856-891.

[17] Erosa, A., L. Fuster, and D. Restuccia (2005). "A Quantitative Theory of the Gender Gap in Wages." Manuscript. University of Toronto.

[18] Fernández, R., and R. Rogerson. (2001). "Sorting and Inequality." Quarterly Journal of Economics, vol. 116, 1305-41.

[19] Haveman, R. and B. Wolfe (1995). "The Determinants of Children Attainments: A Review of Methods and Findings." Journal of Economic Literature, vol. 33, 1829-1878.

[20] Hill, M.S. (1981). "Patterns of Time Use." Mimeo. Ann Arbor: University of Michigan, Survey Research Center.

[21] Hoem, B. (1996). "Some Features of Recent Demographic Trends in Sweden." Mimeo. Statistics Sweden. 
[22] Hofferth, S.L. and D. A. Wissoker (1991). "Price, Quality, and Income in Child Care Choice." Journal of Human Resources, vol. 27, 70-111.

[23] INE, (1999). Encuesta de Fecundidad. Internet address: http://www.ine.es/inebase/cgi/um?M=\%2Ft20\%2Fp317\&O=inebase $\& \mathrm{~N}=\& \mathrm{~L}=$.

[24] Kreyenfeld, M. (2000). "Employment Careers and the Timing of First Births in East Germany." Working paper 2000-004, Max Planck Institute for Demographic Research.

[25] Ljungqvist, L. and T. J. Sargent (1998). "The European Unemployment Dilemma." Journal of Political Economy, vol. 106, 514-50.

[26] McGrattan, E. R. and R. Rogerson (1998). "Changes in Hours Worked Since 1950." Federal Reserve Bank of Minneapolis Quarterly Review vol. 22 (1), pp. 2-19.

[27] Mincer, J. (1962). "Labor Force Participation of Married Women." In Aspects of Labor Economics, edited by H. G. Lewis. Universities-National Bureau Conference Ser., no. 14. Princeton, N.J.: Princeton University Press.

[28] Mincer, J. and H. Ofek (1982). "Interrupted Work Careers: Depreciation and Restoration of Human Capital." Journal of Human Resources XVII (1), 3-24.

[29] O.E.C.D., (1999). Health and Labor Statistics. Electronic resource.

[30] Regalia, F. and J. V. Ríos-Rull (2001). "What Accounts for the Increase in the Number of Single Households?" Mimeo. University of Pennsylvania.

[31] Tauchen, G. 1986. "Finite State Markov-Chain Approximations to Univariate and Vector Autoregressions." Economics Letters 20, pp. 177-181. 


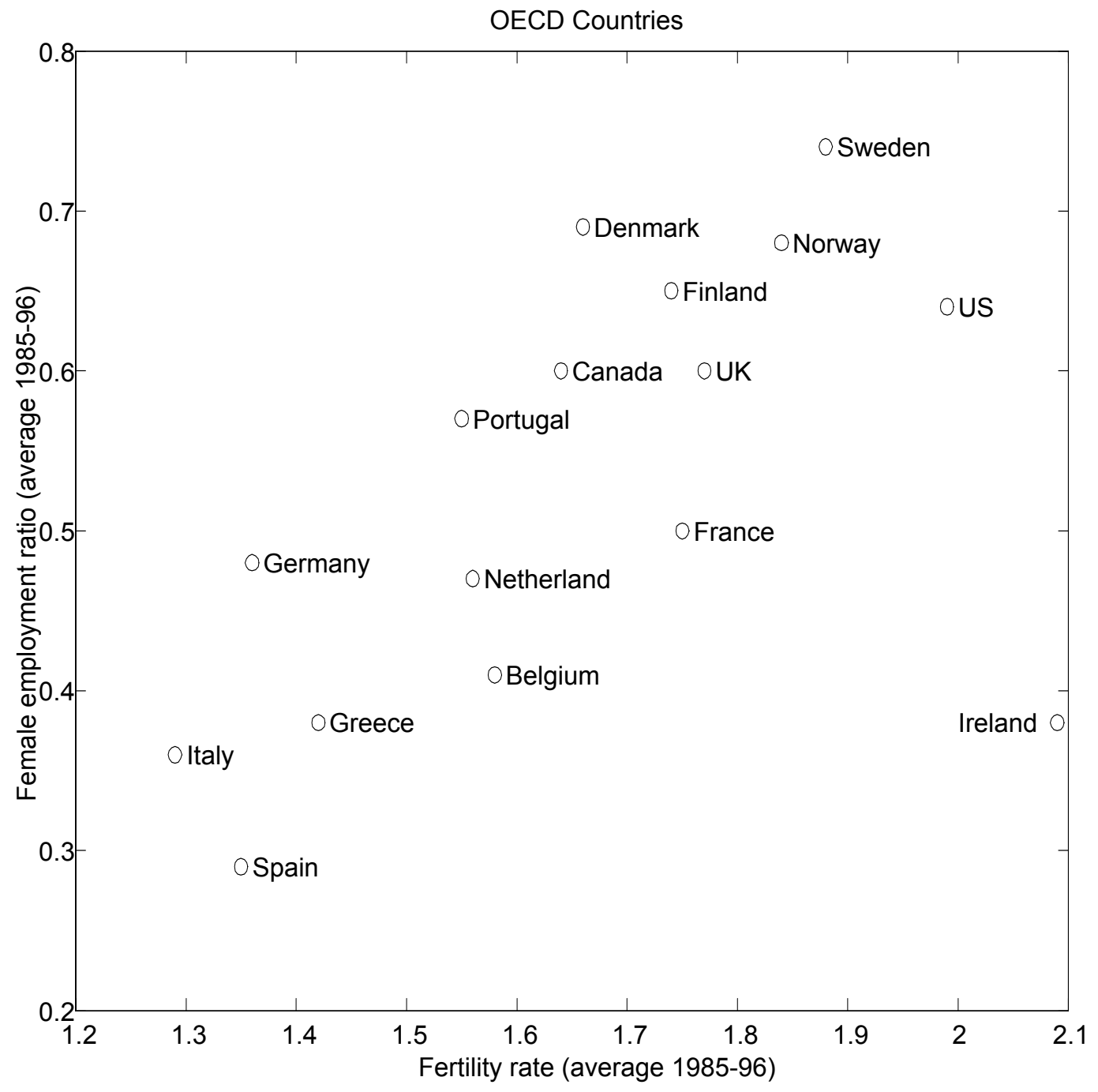

Figure 1: Fertility rates and employment ratios in O.E.C.D. countries (averages of period 1985-96). 


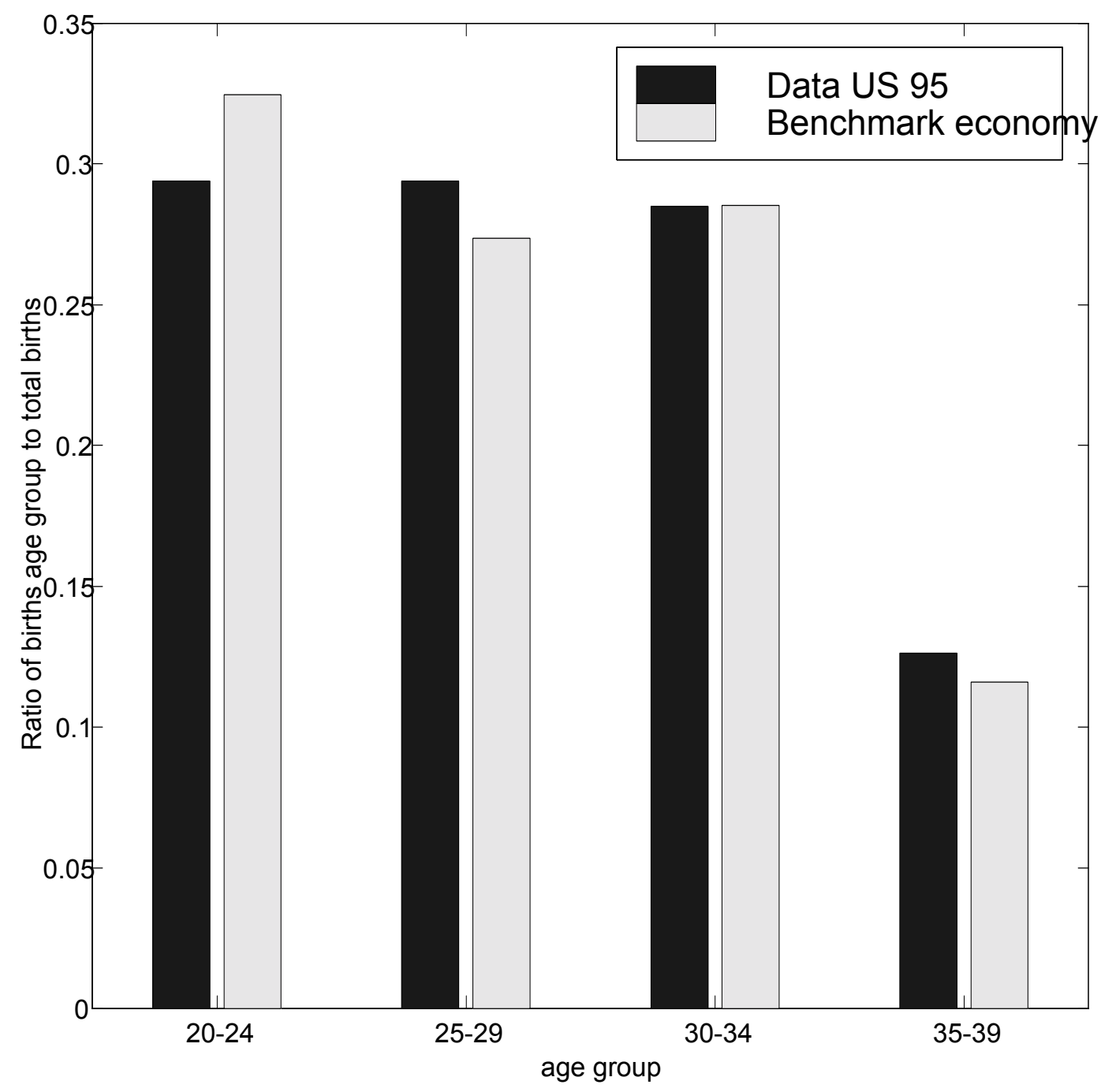

Figure 2: Ratios of births per age group to total births in the U.S. in 1995 and in the benchmark economy. 


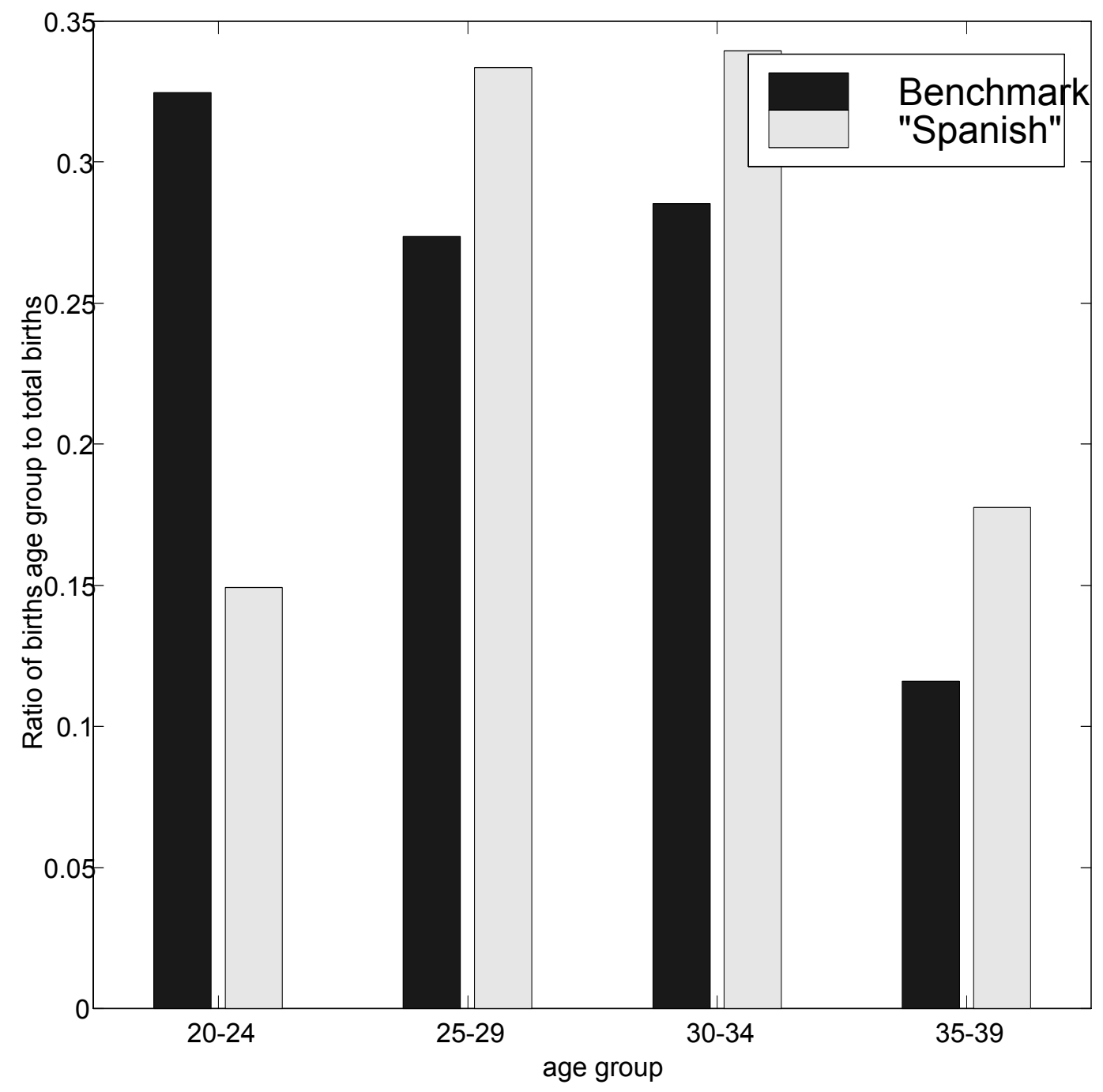

Figure 3: Ratios of births per age group to total births in the benchmark and in the "Spanish" model economies. 


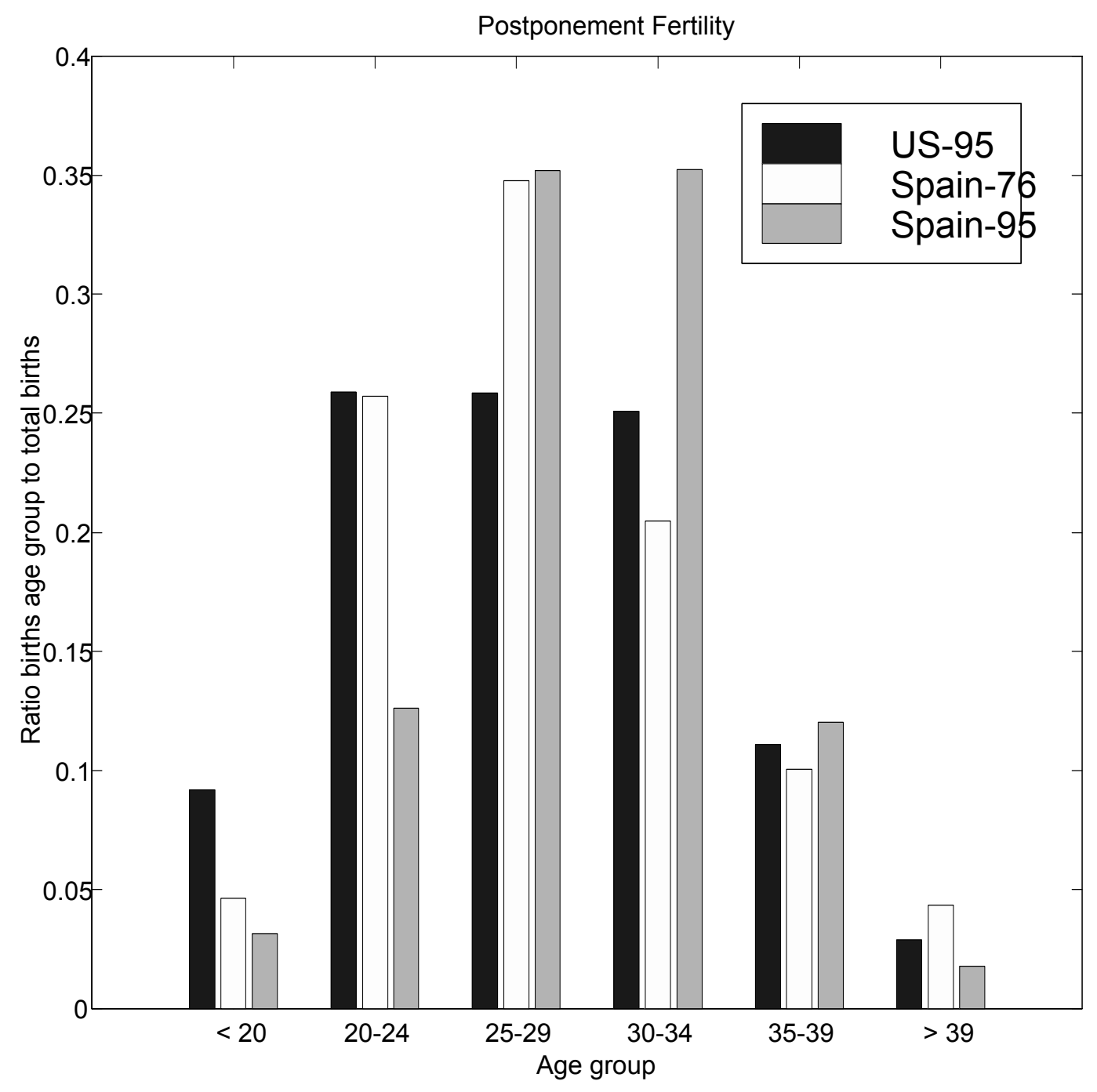

Figure 4: Ratios of births per age group to total births in the U.S. and Spain. 


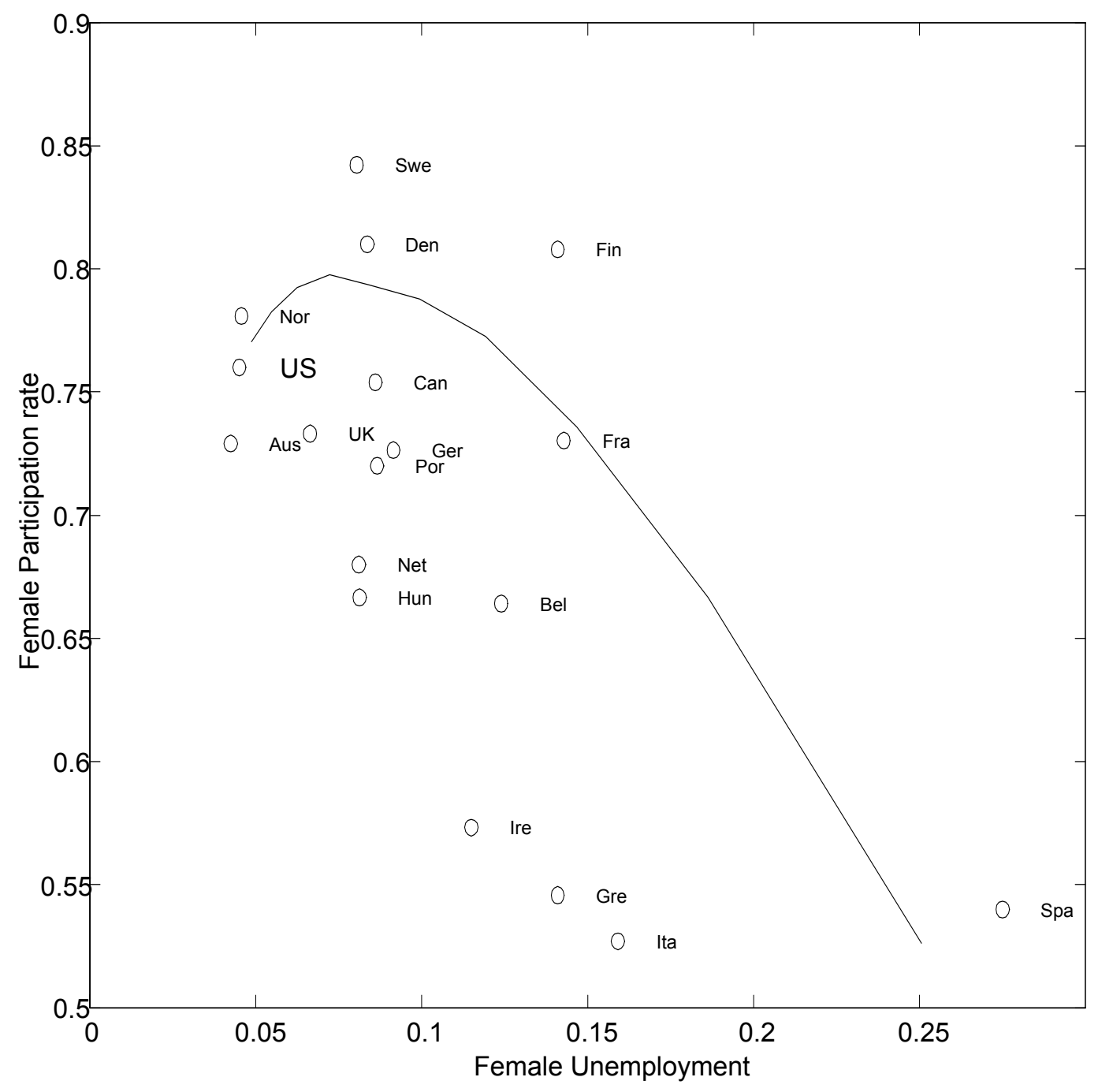

Figure 5: Unemployment and participation rates in O.E.C.D. countries in 1995 and in model economies. 


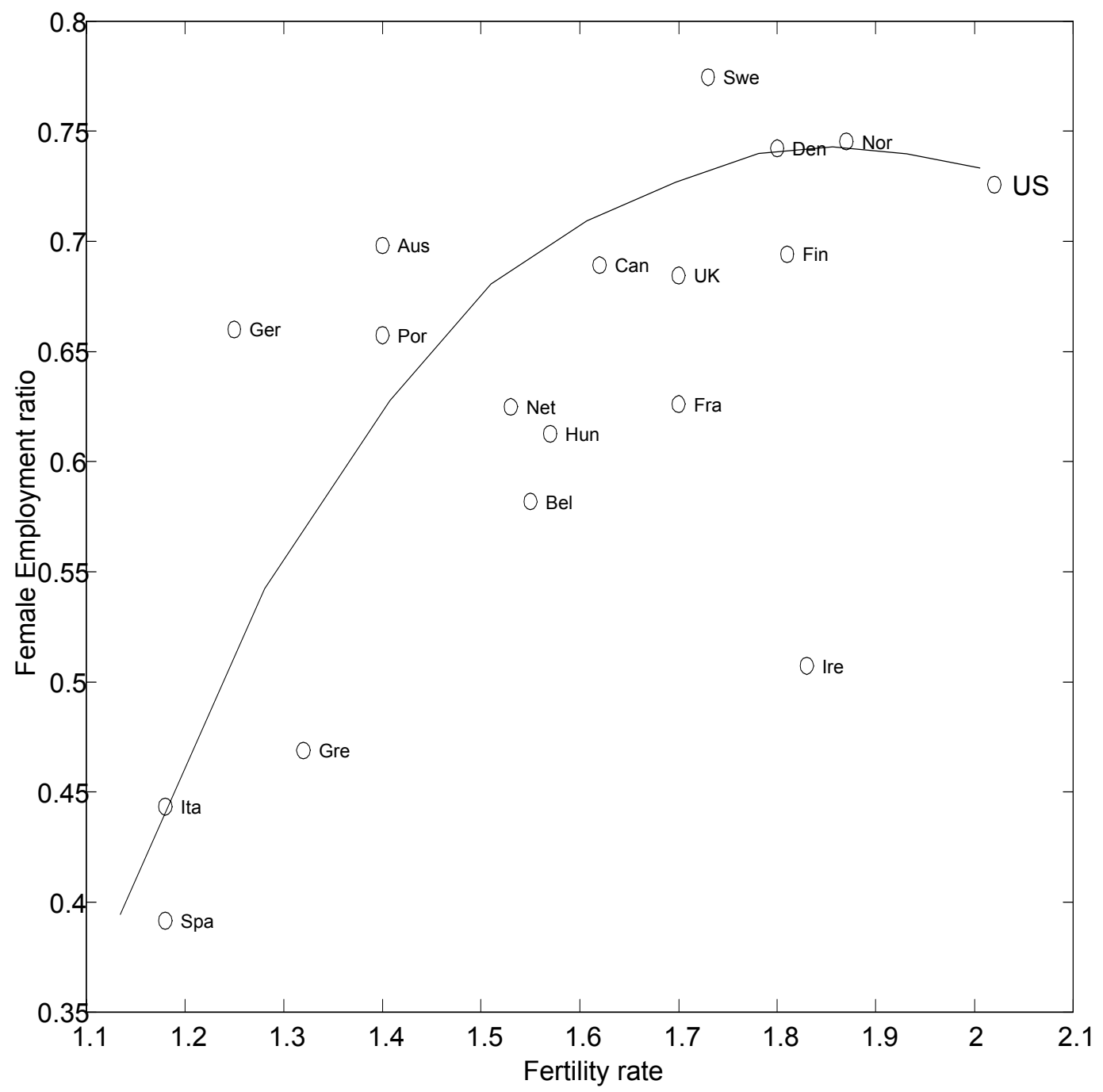

Figure 6: Fertility rates and employment ratios in O.E.C.D. countries in 1995 and in model economies. 


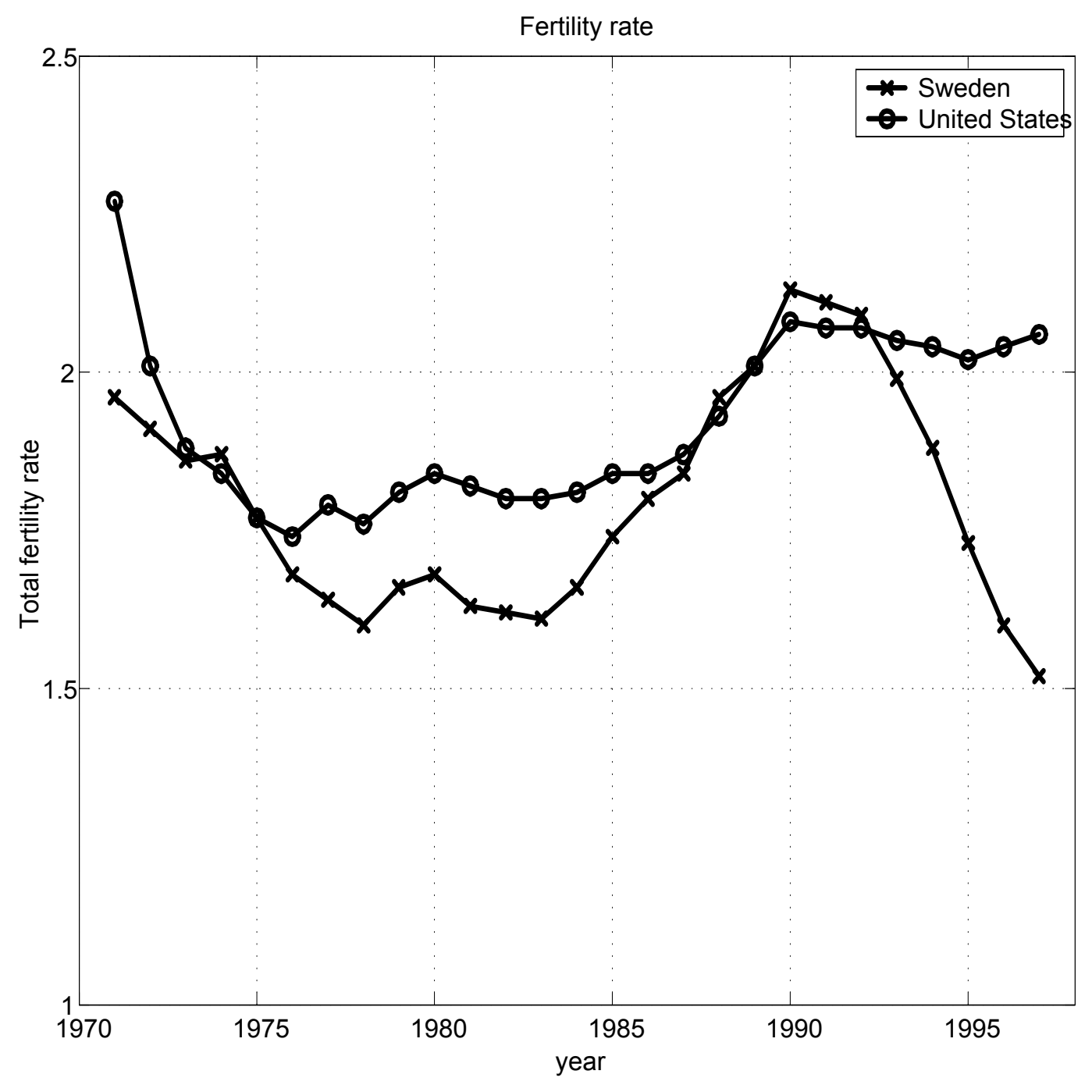

Figure 7: Total fertility rates in the U.S. and Sweden. 


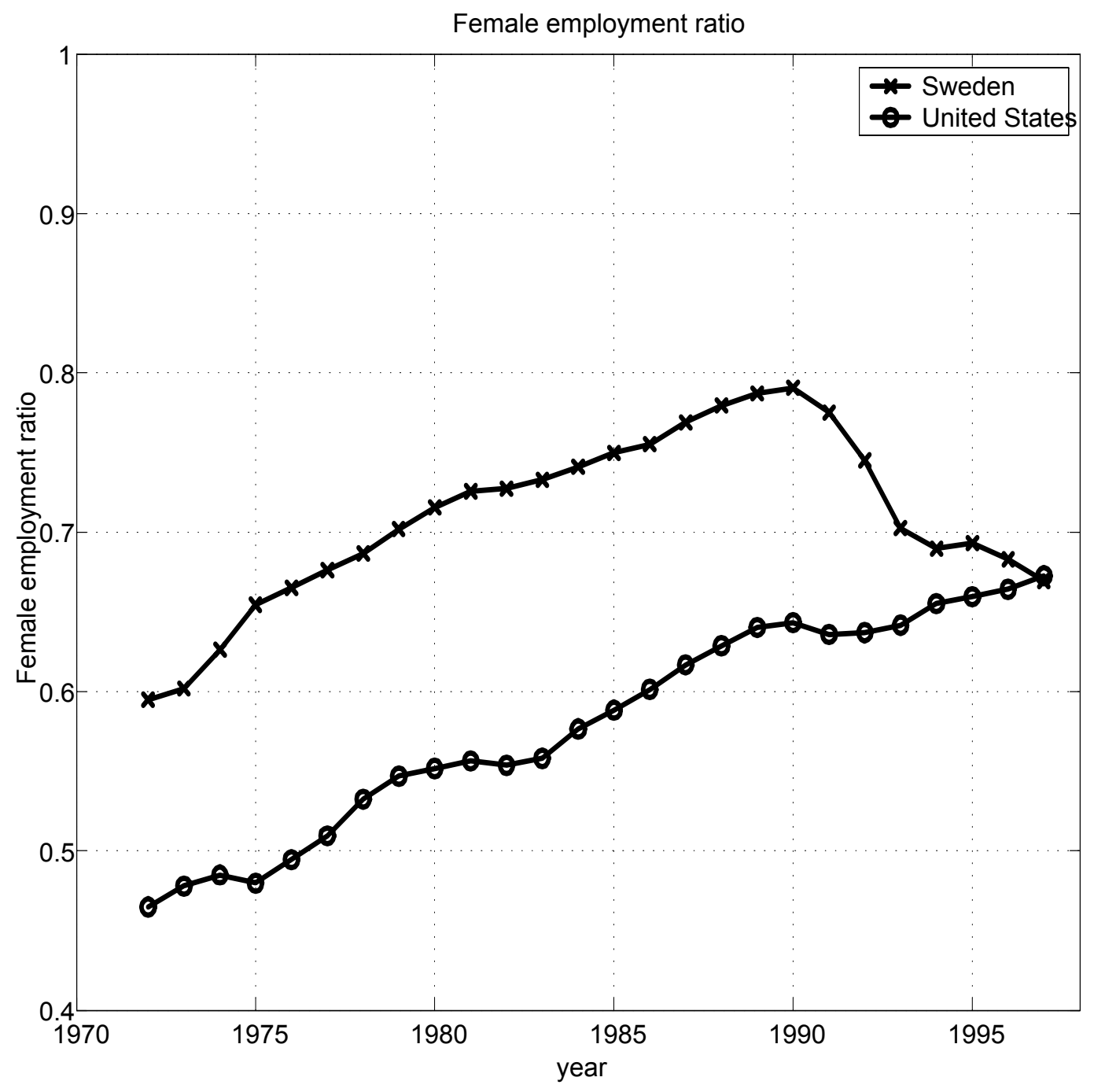

Figure 8: Female employment ratios in the U.S. and Sweden. 


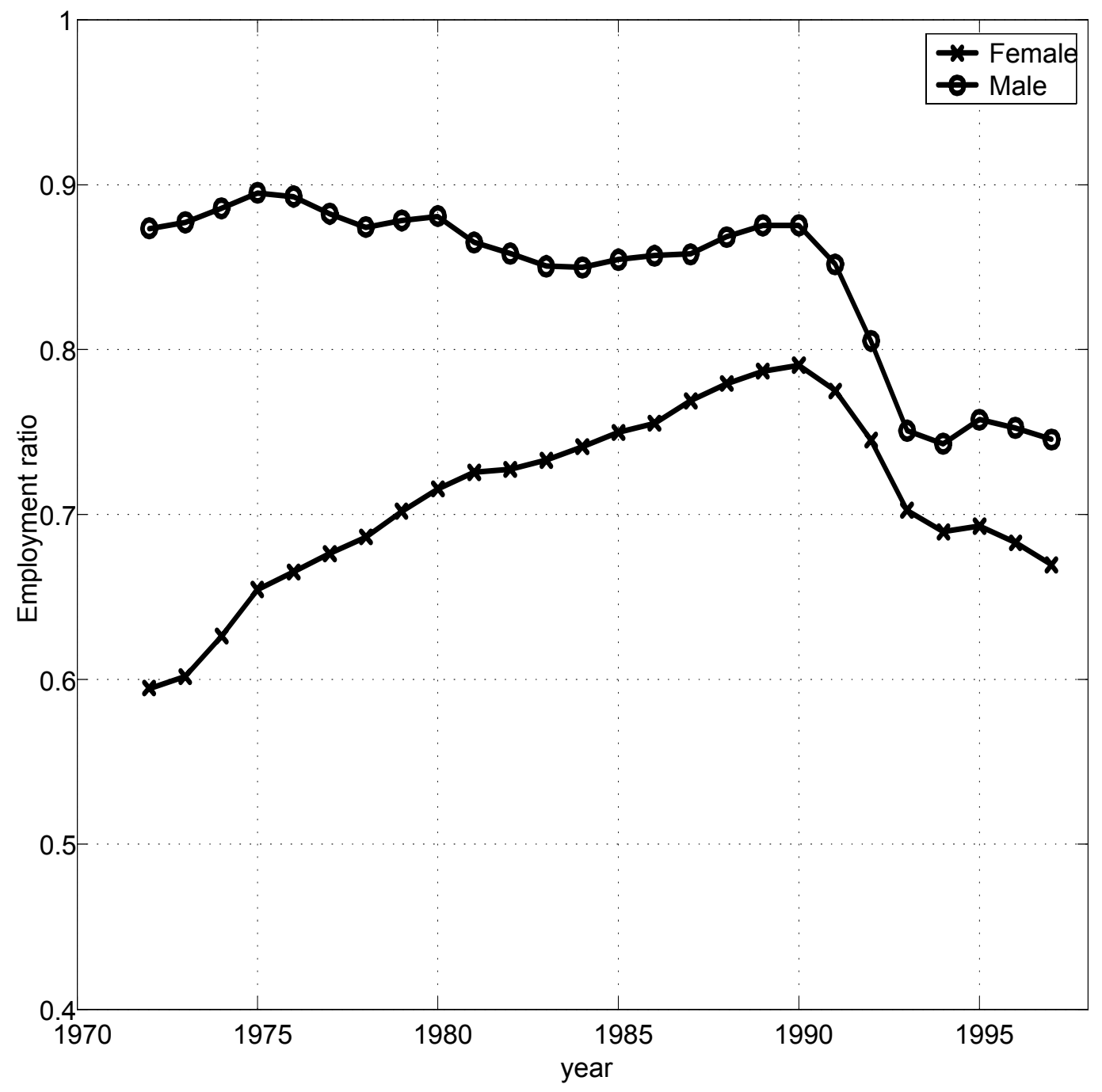

Figure 9: Male and female employment ratios in Sweden. 


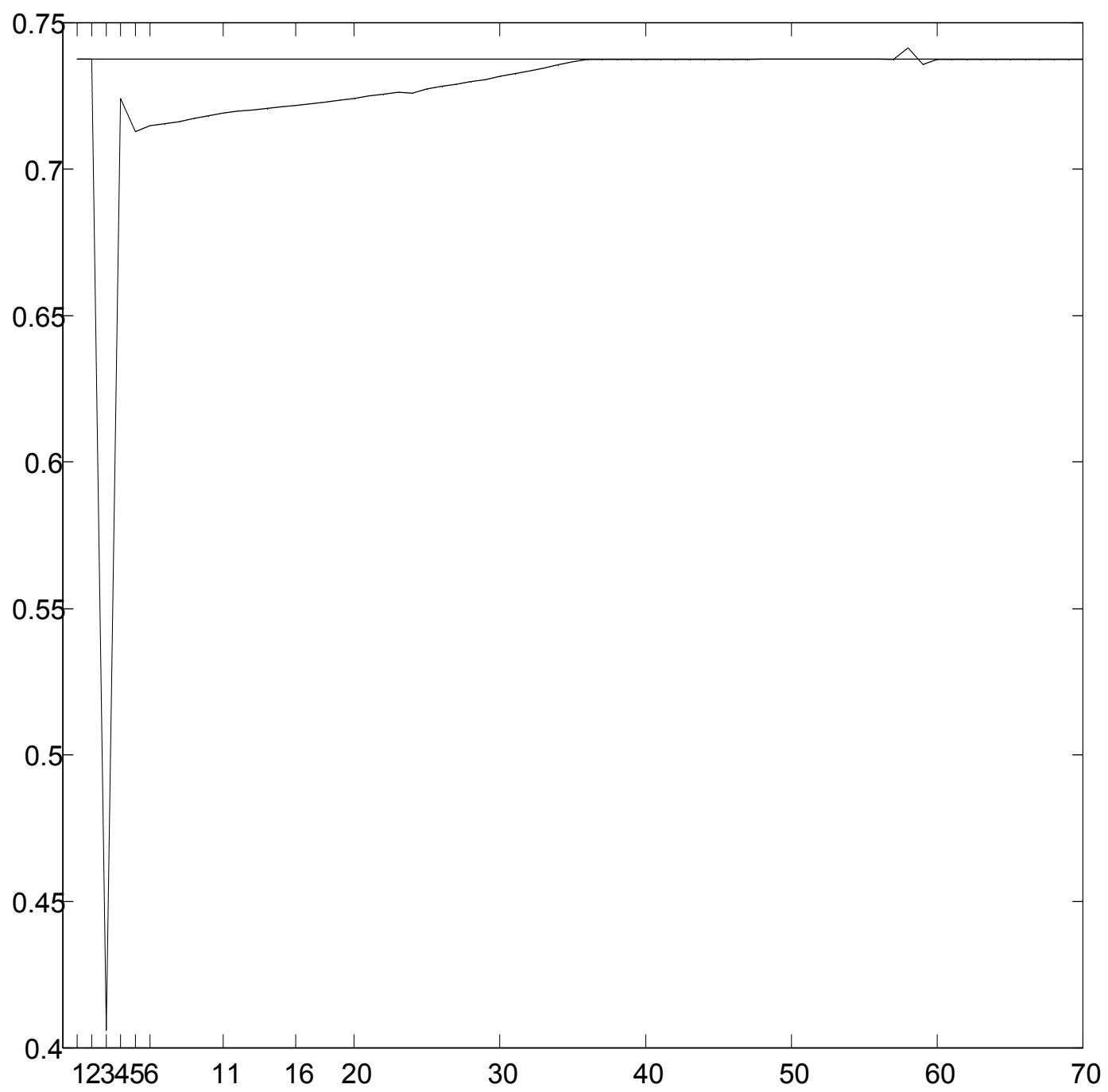

Figure 10: Employment ratio during transition. 


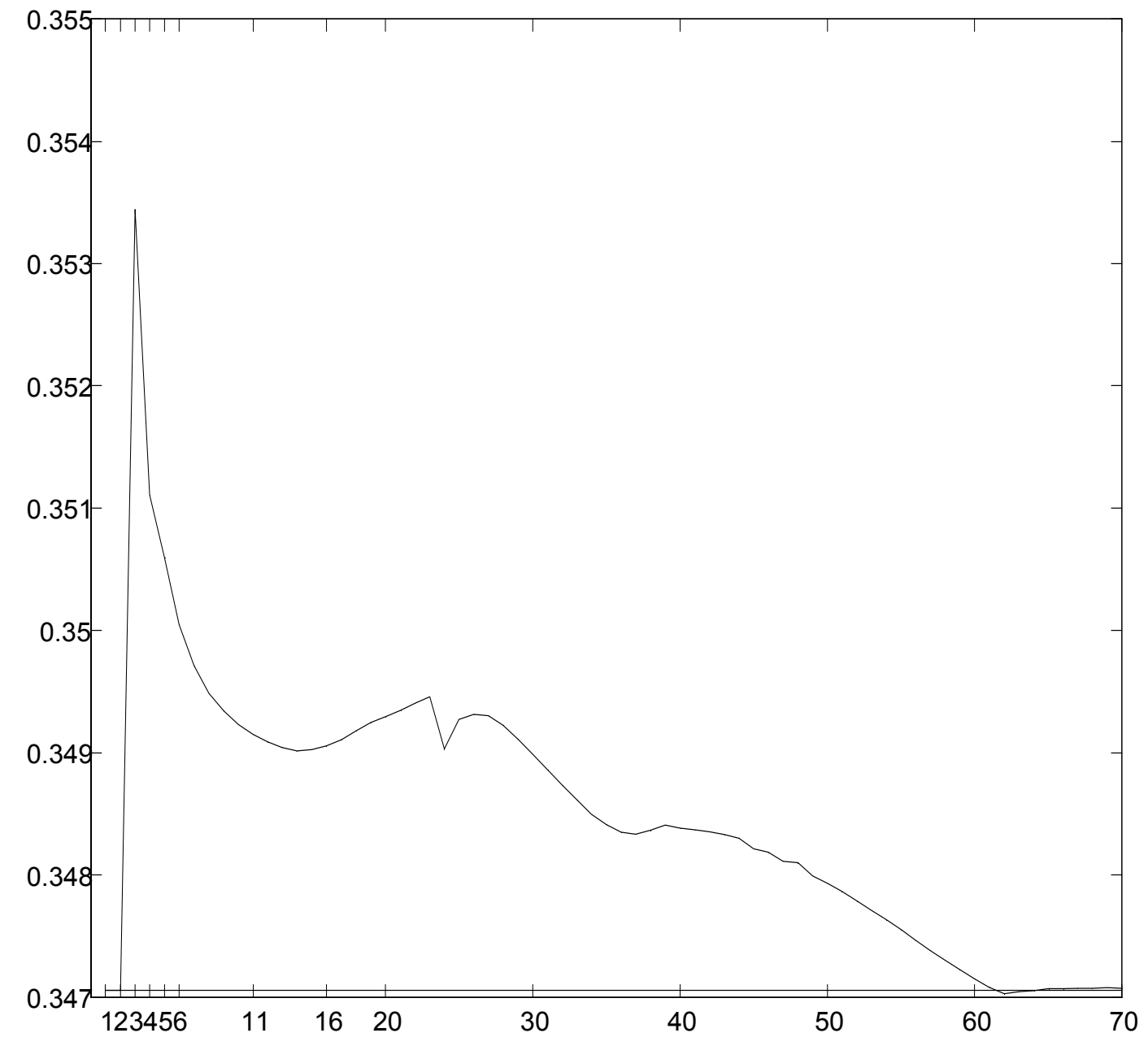

Figure 11: Gini coefficient wages during transition. 


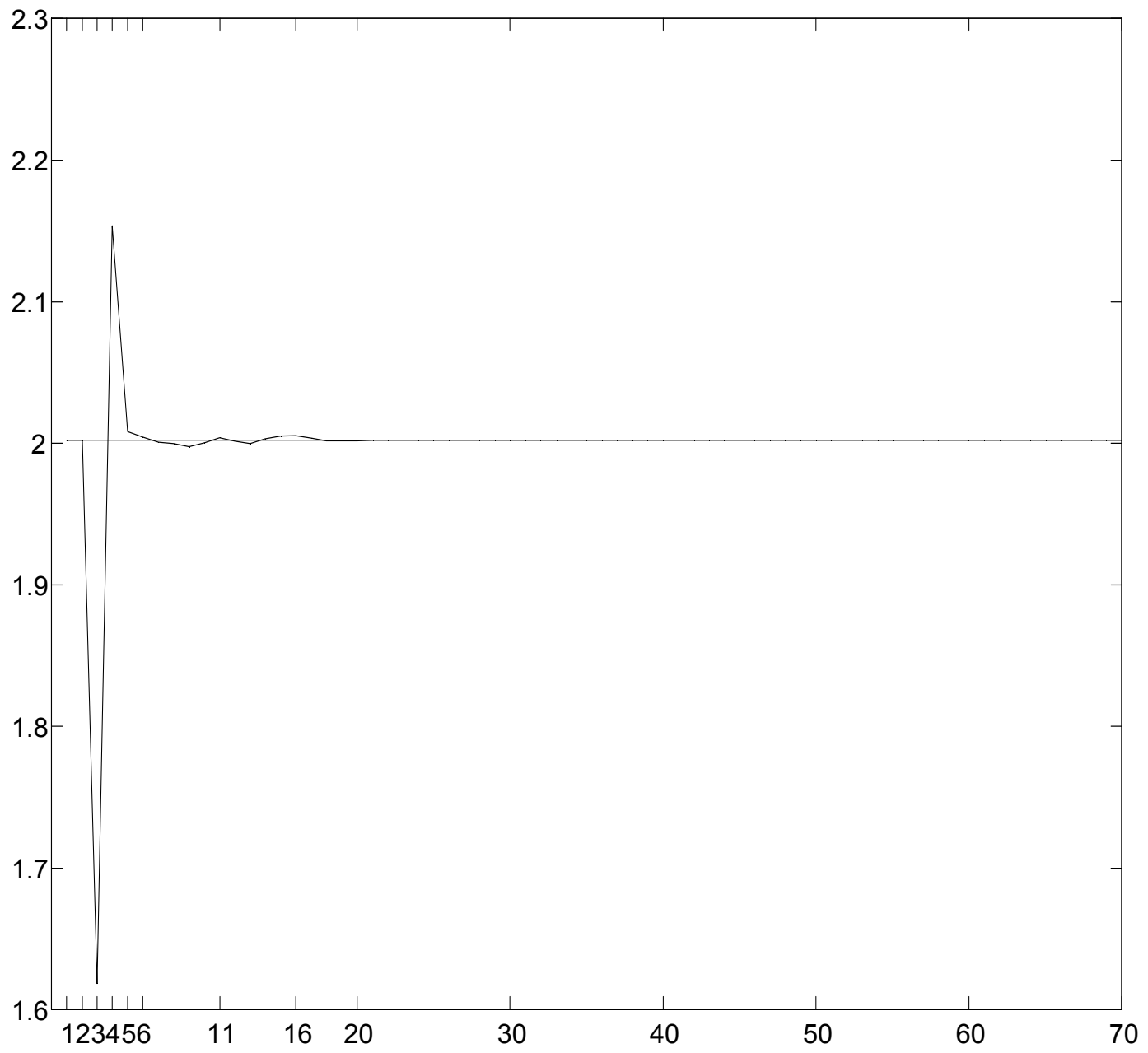

Figure 12: Fertility rate during transition. 